This is a post-peer-review, version of an article published in International Journal of Services and Operations Management, 2020 Vol.36 No.1, pp.42 - 71. The final version is available on Inderscience Publishers at http://dx.doi.org/10.1504/IJSOM.2020.106792. Copyright (C 2020 Inderscience Enterprises Ltd.

\title{
Behavioral operations management - identification of its research program
}

Authors: Jure Erjavec; Peter Trkman

Addresses: Academic Unit for Business Informatics and Logistics, Faculty of Economics, University of Ljubljana, Kardeljeva pl. 17, 1000 Ljubljana, Slovenia

\begin{abstract}
The rise in popularity of the behavioral operations management field has resulted in several attempts to clearly establish this multidisciplinary field. Given the divergent views of what the field actually includes, this paper attempts to contribute to an ongoing debate about the current state of the field as a research field and its future development. The paper uses Lakatos' view that suggests that instead of individual theories, scientific progress should be viewed in the context of research programs, which consist of the hard core and the protective belt. To identify subfields, the paper combines the literature review with a co-citation network analysis of the behavioral operations management field between 1957 and 2015. Six clusters are identified. The Domain base cluster represents the hard core of the field, while five other clusters (Newsvendor, Bullwhip and inventory optimization, Social goals, Supplier relationship, and Organizational behavior) represent its protective belt. In addition to the exploration of existing clusters, the analysis in the paper offers an excellent starting point to identify and position further research questions. A study like this is easily replicable and enables following the evolution of the field.
\end{abstract}

Keywords: behavioral operations management; research program; network analysis; co-citation analysis; cluster analysis 
Most operations in organizations and supply chains depend on human decision-making. A deeper understanding of behavioral issues should enable firms and supply chains to make better decisions and operate more efficiently. Yet the methods and models that support decision-making often disregard the role of human behavior or do not study it in a systematic manner (Croson et al., 2013; Hämäläinen et al., 2013). As a response to this problem, the field of behavioral operations management (BOM) has attracted increased attention in the last decade. The rise in popularity of the topic has been demonstrated by its coverage in several special issues, editorials, invited notes (Bendoly et al., 2006; Croson et al., 2013; Gans and Croson, 2008; Katsikopoulos and Gigerenzer, 2013; Zhao et al., 2013) and special tracks on operations management conferences. Furthermore, Melnyk et al. (2017) promoted the use of behavioral theories as a possible means for remedying several issues with operations and supply chain management theory validation research, since they offer a view of decision-making as a social process influenced by the actions of others, with service operations specifically benefiting from behavioral theories (Walker et al., 2015).

The BOM research encompasses several different fields such as cognitive psychology, social psychology, group dynamics, and system dynamics (Bendoly et al., 2010). While this is beneficial, it could lead to the argument that BOM is "everything and nothing." Similar to Lyytinen and King (2004), who studied the information systems field at a similar stage of development to where BOM is now, we argue that the field of BOM should embrace this fact as a great source of strength, because diversity and intellectual quality drive strong results.

There have been several attempts to define the field of BOM and what it encompasses in dedicated papers (Bendoly et al., 2010; Bendoly et al., 2015; Croson et al., 2013; Gino and Pisano, 2008; Katsikopoulos and Gigerenzer, 2013) or as a part of papers dealing with behavioral operations research (Becker, 2016). Authors in those papers used qualitative assessments when defining the core of the field and what it deals with. Unfortunately, nature-of-the-field commentaries are unlikely to help clarify or resolve fundamental issues that underpin the debate. They are often based on idiosyncratic views that are difficult to either justify or refute. Aside from the quality of the rhetoric they manifest, it is impossible to measure which view is better (adapted from Weber, 2006).

Such openness can lead to arbitrariness hampering the progression of BOM (Gold, 2014). There would continue to be little agreement of the domain and the consensus definitions, which would lead to a lack of clarity as to the 
scope of BOM (Zacharia et al., 2014). Such an identity crisis was not a unique or isolated phenomenon but rather was part of a more widespread anxiety about the nature and role of BOM (Larsen and Levine, 2005). We investigate which themes or ideas represent the center of BOM and its zones of coherence (see Larsen, 2005). We attempt to clearly identify the current state of BOM in such a way that it will be possible to continually monitor the structure and development of the field.

We contribute to an ongoing debate about the current state of BOM as a research field and its future development. Similar to Bernroider et al. (2013), who studied information systems, our paper investigates how BOM has emerged as the product of interdisciplinary discourses to better understand the diversity in BOM research. Such an investigation helps in identifying the disciplinary status of BOM, with its relevance and influence forming the basis of its identity and legitimacy (see Hassan, 2014). An agreement of the basic elements that characterize the BOM field, distinguish it from other fields, and connect it with its reference and associated fields is needed (Hassan, 2014). Without that, BOM could become a broad label under which a mixture of research is housed rather than a tool used to explain and predict a unique set of empirical phenomena (Shane and Venkataraman, 2000).

Any discipline has a strong and inherent interest in improving the understanding of itself (Straub, 2006). In line with Lakatos' (1976) view on research programs, we use co-citation analysis and contribute to the understanding of the intellectual base and the main clusters of research themes within the field and their interrelationships (Raghuram et al., 2010). The analysis of six major clusters and the connections between them enables us to stipulate the hard core of BOM, the topics that form its current protective belt, and the possible paths for further development.

The structure of this paper is as follows. In the next section, the development of BOM is outlined, and the justification of the need for this literature review paper is argued. In section three, the methodology is presented. Section four presents the results of the analysis, with each of the six clusters presented in detail. We offer a discussion on the findings in section five and present conclusions in section six.

\section{Behavioral operations management}

While research on behavioral issues in operations management (OM) existed long before 2006 (Boudreau, 2003; Mingers, 2000), the term behavioral operations management was first used in an editorial of a special issue on behavior in OM (Bendoly et al., 2006). However, while the theoretical core of the general OM discipline has matured (Hämäläinen et al., 2013), BOM's core needs further development (Tokar, 2010).

Gino and Pisano (2008) suggest that multiple approaches can and should be used to expand research in BOM, such as improving awareness within the OM discipline, collaboration between scholars in different fields, and training $\mathrm{OM} \mathrm{PhD}$ students in behavioral decision research. Additionally, Sodhi and Tang (2014) argue that behavioral experiment is an important methodology in different stages of OM doctoral students training, while Melnyk et al. (2017) identify behavioral experiments as one of the analytical methods that provide better opportunities to align data analysis strategy with the identified research problem. Furthermore, BOM is the 
bridge between traditional models and the newer observational findings (Gans and Croson, 2008), and it also aims to understand the decision-making processes of managers and to generate interventions that improve operations (Katsikopoulos and Gigerenzer, 2013). More recently, Croson et al. (2013) defined BOM as the study of potentially non-hyper-rational actors in an operational context, while Bendoly et al. (2015) define it as an "exploration of interaction of human behaviors and operational systems and processes."

BOM is prominently an interdisciplinary endeavor, and it draws on multiple reference fields, such as experimental and behavioral economics, judgement and decision making from psychology, and organizational behavior and decision analysis from management (Gans and Croson, 2008; Katsikopoulos and Gigerenzer, 2013). It is one of the few subfields of OM to actually cross boundaries (Singhal and Singhal, 2012). In such cases, researchers can obtain multiple perspectives by investigating different parts of a system, by employing different research paradigms, or by using different subsets of the same data (Singhal and Singhal, 2012).

Furthermore, Bendoly et al. (2010) defined the main bodies of knowledge outside of OM, namely cognitive psychology, social psychology, group dynamics, and system dynamics. Even though most of the papers in the field have traditionally focused on inventory, the recent papers encompass a broader variety of topics, including topics from revenue management, product development, quality management and control (Baker et al., 2017; Witt et al., 2017), production and workflow management, procurement, humanitarian logistics (Sankaranarayanan et al., 2018), services (Le, 2017), supply chain management, and risk analysis and process improvement (Bendoly et al., 2006; Croson et al., 2013; Gino and Pisano, 2008). This diversity makes a clear classification of BOM research even more crucial.

All of these efforts do not answer the crucial questions: what is the current position, and even more importantly, what is the future of BOM? The success of BOM can lead to concerns that the distinct research contribution of BOM could become either lost or non-distinct from other fields. We do need suggestions as to how the field should respond to these concerns and should develop a skeletal framework for a future agenda for BOM as a whole (adapted from Walsham, 2012).

Since BOM is a relatively novel field, it is interesting to look at the relevant literature from general OM and related fields (e.g., information systems management and supply chain management) that faced similar struggles in establishing the legitimacy and scope of their fields. BOM is in a similar position to the one that the discipline of production and OM was in the nineties, whereby they had tried for 30 years to establish themselves as disciplines distinct from operations research, management science, and industrial engineering. At that time, skeptics argued that production and OM had failed to develop their own bodies of literature and lacked distinct intellectual structures, and there was little appreciation of what they stood for (Pilkington and Liston-Heyes, 1999). Research on BOM (similar to entrepreneurship research 10 years ago) has been often characterized as diverse and fragmented, with no widely accepted categorization of different streams (adapted from Schildt et al., 2006). Such a lack of clear research trajectories endangers the growth of BOM as a scholarly endeavor. If we are unable to comprehend the nature, importance, and distinctiveness of the role being served by BOM, then it is unlikely that it will establish its legitimacy (Sidorova et al., 2008).

In establishing BOM's legitimacy, the theory development through falsification (Popper, 1972) and the concept of revolutionary paradigm change (Kuhn, 1962) provide an incomplete approach for analyzing changes in focus and growth in knowledge (adapted from Burgess et al., 2006). With the divergent views of what BOM actually includes, we suggest using the view of Lakatos, who suggested that scientific progress be viewed in the context of research programs instead of individual theories (Lakatos, 1976). The hard core is the "unfalsifiable central tenets," the core assumptions upon which all work within the discipline is based. The protective belt is the surrounding set of assumptions that can be subject to negotiation and amendment (Lakatos, 1976). In general, the use of multiple research paradigms to guide the research in a certain discipline is beneficial (Drejer et al., 2000; Singhal and Singhal, 2012). In other words, a discipline can be divided into many different groups (some stronger than others) that each have their unique approach to the discipline in question (Drejer et al., 2000). 
As in all emerging fields, BOM includes different theoretical interpretations of the study object. Over time, this phase should be replaced by a normal science period during which research is more solid and structured (Arlbjørn and Halldorsson, 2002). This is even more crucial for a field that does not relate directly to a certain problem or field within OM (e.g., inventory management or process optimization) but rather attempts to be overarching.

BOM's long-term legitimacy thus depends on its recognition within and outside the OM community. For this to occur, a clear identification of both the hard core and the protective belt is needed. Without such a conscious attempt, research can degenerate into simple data dredging on the ad hoc execution of various behavioral experiments or surveys for whatever real or fictitious reason a researcher can come up with (Dunn et al., 1994; Flynn et al., 1990).

For other fields, this identification was often done very superficially. For example, a paper on logistics research only argued very loosely that the hard core belongs to the analytical approach, while systems' thinking is a methodological approach that cannot be called a theory in the analytical sense (Gammelgaard, 2004). Even the papers using the Lakatosian view in an attempt to determine the hard core and protective belt in related fields usually rely almost entirely on the opinion of a single author or at best on interviews of selected academic scholars and business executive across disciplines (Zacharia et al., 2014). A typical example in OM is Drejer et al. (2000), who looked at the convergence and divergence of research in OM in Scandinavia, the United States, and the United Kingdom. The three different research traditions were described and analyzed separately and were then compared based solely on the authors' opinions.

Rare attempts have been made to approximate this distinction for the research areas of supply chain management and logistics (Gold, 2014). For example, Veit et al. (2017) classified the diversity of business process management research issues and functional areas, while Recker (2014) distributed previously postulated assumptions in the core and protective belt. Still, the first study is based solely on the authors' opinions on how to group papers, while the second distributes the seven key assumptions (axiomatic principles) and does not enable the delineation of research sub-fields. Similarly, in the case of supply chain management, the work of Burgess et al. (2006) suggests that the hard core is based in the "operations management-manufacturingprocess-positivist" nexus, while numerous other activities are within the protective belt. Gold (2014) provides just such an illustrative application on the selection of four research papers. In the case of BOM, similar to supply chain management (Zacharia et al., 2014), the protective belt around BOM seems very much in flux due to disparate disciplines that study BOM.

Therefore, we use co-citation analysis to identify the hard core and protective belt of the field. Such an approach enables one to group the papers and identify the relationships between clusters and their closeness and thus provides the basis on which to interpret what the core of the field is along with its current protective belt. The approach is easily replicable and enables researchers to follow the field's development.

\section{Methodology}

We gathered data from the Web of Science database and performed citation and co-citation analysis. Citation analysis was used to outline the field by examining its basic descriptive statistics such as the number of publications per year, the authors and journals with highest numbers of publications, and the most-cited papers. The main part of the analysis was the co-citation analysis, which was used to identify different clusters (communities) within the field.

\subsection{Data collection}

An initial literature review (section two) provided a definition of the field and a list of topics that are covered within the field. In the next step, a list of keywords was determined. Since the initial literature review showed 
that the field is highly multidisciplinary, we separated the keywords into two groups. The first group of keywords included the word behavioral/behavioural, together with expressions directly linked to OM. The second group of keywords included combinations of keywords from OM, together with keywords from other identified disciplines. There were five different keywords in the first group and 108 different keyword combinations in the second group. The full list of keywords is in Table 1.

Table 1: Keywords

\begin{tabular}{|c|c|c|}
\hline Independent keywords & $\begin{array}{l}\text { "behavioral (behavioural) operations management" } \\
\text { "behavioral (behavioural) supply chain management" } \\
\text { "behavioral (behavioural) operations" } \\
\text { "behavioral (behavioural) operations research" } \\
\text { "behavioral (behavioural) supply management" }\end{array}$ & \\
\hline $\begin{array}{l}\text { Keywords from OM } \\
\text { discipline }-1^{\text {st }} \text { part } \\
\text { of the combination }\end{array}$ & $\begin{array}{l}\text { “operations management” } \\
\text { “operations research" } \\
\text { “supply chain management” }\end{array}$ & $\begin{array}{l}\text { "logistics" } \\
\text { "production management" } \\
\text { "inventory management" }\end{array}$ \\
\hline $\begin{array}{l}\text { Keywords from other } \\
\text { identified disciplines } \\
-2^{\text {nd }} \text { part of the } \\
\text { combination }\end{array}$ & $\begin{array}{l}\text { "behavioral (behaviourial) experiment" } \\
\text { "human experiments" } \\
\text { "behavioral (behaviourial) risk" } \\
\text { "behavioral (behaviourial) decision making" } \\
\text { "behavioral (behaviourial) issues" } \\
\text { "human behavior (behaviour)" } \\
\text { "personal traits" } \\
\text { "irrational behavior (behaviour)" } \\
\text { "intuition" }\end{array}$ & $\begin{array}{l}\text { "human judgement" } \\
\text { "judgement heuristics" } \\
\text { "social preferences" } \\
\text { "decision bias" } \\
\text { "cognitive limitations" } \\
\text { "individual preferences" } \\
\text { "bounded rationality" } \\
\text { "cognitive bias" } \\
\text { "psychology" }\end{array}$ \\
\hline
\end{tabular}

In February 2016, we performed a search of the Web of Science Core Collection database for all included papers. Web of Science was selected because it offers reliable coverage and historical overviews at the journal, article, and cited-reference levels (Norris and Oppenheim, 2007). We used the "topic" (TS) search category in Web of Science, which includes title, abstract, author keywords, and keywords plus. We identified 224 papers; we read through abstracts of all papers and excluded only those that were clearly outside the BOM field such as Holden et al. (2015) and Nikolaidis (2015). After the exclusions, 183 papers remained (the list is available from the authors on request).

\subsection{Co-citation analysis}

We used co-citation analysis in order to identify different clusters of topics within BOM. Co-citation is the frequency with which two documents are cited together in other documents (Small, 1973). It is based on the premise that when two items appear together frequently, their content is strongly related (McCain, 1990). The connections present relationships in the knowledge structure of a discipline and are well suited to investigate 
how intellectual structures evolve (White, 1990). Co-citation analysis is nowadays the dominant method for the empirical study of the development of research fields (Gmür, 2003), with content analysis as its alternative (Dharamdass and Fernando, 2018).

Co-citation patterns can be used to map out in great detail the relationships between different key ideas (Small, 1973). The co-citation method uses the initial papers and the list of references of all those initial papers when searching for frequent co-citation pairs. As opposed to the simple counting of citations, this method discards publications that are frequently cited but are isolated in terms of content (Gmür, 2003). After the publications and their co-citations are measured, they can be aggregated into clusters. These can be then used to visually present cluster relationships, the strength of these relationships, and the relative position of each cluster (Bernroider et al., 2013). The results also reveal the main fields and schools of thought and can help with identifying the paradigm shifts within a discipline (Pasadeos et al., 1998).

For the co-citation analysis, the data were prepared and organized with Bibexcel (Persson et al., 2009), which is a bibliometric analysis tool. It is used to analyze bibliographic data and also to prepare it for use in other processing tools. The data were then analyzed and visualized with Pajek software, which is a large network analysis and visualization tool (De Nooy et al., 2011). As the pairs of works need to be frequently co-cited (Small, 1973), we excluded publication pairs with low co-citation occurrences.

To identify different clusters, we used the Louvain method for community detection (Blondel et al., 2008), which is a heuristic method based on modularity optimization. Zupic and Cater (2015) identify the Louvain method as one of the two effective community-finding algorithms in the management and organizational sciences (the second being the Islands algorithm).

We also measured modularity of the network, which is a measure of the possible presence of clearly identifiable communities (community structure). Positive modularity indicates the possible presence of community structure (Newman, 2006), with values between 0.3 and 0.7 indicating strong community structure (Newman and Girvan, 2004).

We used the Louvain method with resolution parameters set to different values between 0.5 and 2 (in increments of 0.5 ), and each time, we ran the algorithm with several restarts. We also tried several different values for the minimum amount of co-citation occurrences, ranging from 1 to 5 (in increments of 1). Different combinations of resolution parameters and a minimum amount of co-citation occurrences gave several possible cluster configuration results. Most of the results had modularity close to or under the 0.3 threshold. Out of all of the results, we identified three possible options. Two of them (resolution parameter 0.5, minimum amount of cocitation occurrences 5; and resolution parameter 0.5, minimum amount of co-citation occurrences 4) had modularity within the threshold ( 0.5372 and 0.5690 , respectively); however, they only had 2 clusters. Therefore, we used the result with 6 clusters. It had the resolution parameter 1 and minimal amount of co-citation occurrences 3 , with modularity 0.4568 .

We measured the correlation between partitions with different restarts with Cramér's V (Cramér, 1945) measure. The value of the measure was 1.000 , which means that correlation between partitions is at the highest level possible, and we therefore used these results for further analysis.

\section{$4 \quad$ Results}

The field of BOM has gained increased popularity in the last decade, as we can see from Figure 1 (data from January, 2018). Only 15 papers were published before 2000, with the first one reaching back to 1957. 
Figure 1: Number of papers per year

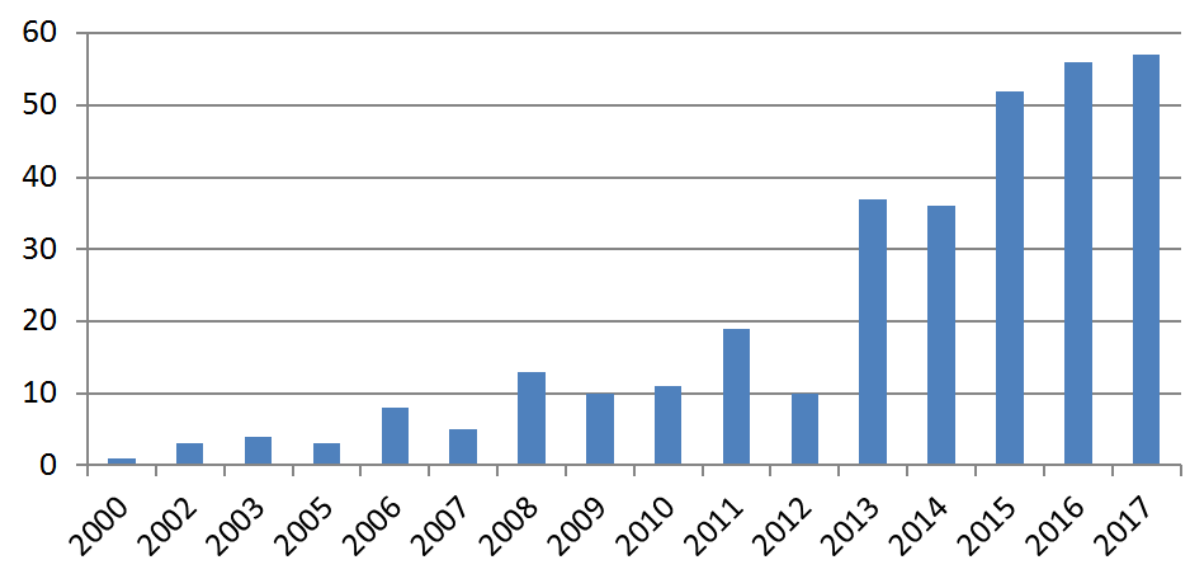

The main part of our research was co-citation analysis, in which we firstly identified the most-cited papers, which are shown in Table 2. The papers are ranked in order of the local citation score (LCS), which shows how many times they were cited in the papers that were included in the analysis. Global citation score (GCS-W) shows the number of times the papers were cited in the Web of Science Core Collection. GCS-G shows the number of times the papers were cited in Google Scholar. 
Table 2: Most cited papers

\begin{tabular}{|c|c|c|c|c|c|}
\hline Title & Author & Journal / Year & $\begin{array}{l}\text { LC } \\
\text { S }\end{array}$ & $\begin{array}{l}\text { GCS- } \\
\text { W }\end{array}$ & GCS-G \\
\hline $\begin{array}{l}\text { Decision bias in the newsvendor } \\
\text { problem with a known demand } \\
\text { distribution: Experimental evidence }\end{array}$ & $\begin{array}{l}\text { Schweitzer, ME; } \\
\text { Cachon, GP }\end{array}$ & $\begin{array}{l}\text { Management Science, } \\
2000\end{array}$ & 38 & 262 & 612 \\
\hline $\begin{array}{l}\text { Behavior in operations management: } \\
\text { Assessing recent findings and } \\
\text { revisiting old assumptions }\end{array}$ & $\begin{array}{l}\text { Bendoly, E; } \\
\text { Donohue, K; } \\
\text { Schultz, KL }\end{array}$ & $\begin{array}{l}\text { Journal of Operations } \\
\text { Management, } 2006\end{array}$ & 36 & 124 & 294 \\
\hline $\begin{array}{l}\text { Learning by doing in the newsvendor } \\
\text { problem: A laboratory investigation of } \\
\text { the role of experience and feedback }\end{array}$ & $\begin{array}{l}\text { Bolton, G.E.; } \\
\text { Katok, E. }\end{array}$ & $\begin{array}{l}\text { Manufacturing \& } \\
\text { Service Operations } \\
\text { Management, } 2008\end{array}$ & 25 & 64 & 192 \\
\hline $\begin{array}{l}\text { Bodies of knowledge for research in } \\
\text { behavioral operations }\end{array}$ & $\begin{array}{l}\text { Bendoly, E.; } \\
\text { Croson, R.; } \\
\text { Goncalves, P.; } \\
\text { Schultz, K. }\end{array}$ & $\begin{array}{l}\text { Production and } \\
\text { Operations } \\
\text { Management, } 2010\end{array}$ & 23 & 49 & 125 \\
\hline $\begin{array}{l}\text { Bounded rationality in newsvendor } \\
\text { models }\end{array}$ & Su, X.M. & $\begin{array}{l}\text { Manufacturing \& } \\
\text { Service Operations } \\
\text { Management, } 2008\end{array}$ & 23 & 81 & 204 \\
\hline $\begin{array}{l}\text { Newsvendor "pull-to-center" effect: } \\
\text { Adaptive learning in a laboratory } \\
\text { experiment }\end{array}$ & $\begin{array}{l}\text { Bostian, A.J.; Holt, } \\
\text { C.A.; Smith, AM }\end{array}$ & $\begin{array}{l}\text { Manufacturing \& } \\
\text { Service Operations } \\
\text { Management, } 2008\end{array}$ & 22 & 49 & 130 \\
\hline $\begin{array}{l}\text { Behavioral causes of the bullwhip } \\
\text { effect and the observed value of } \\
\text { inventory information }\end{array}$ & $\begin{array}{l}\text { Croson, R.; } \\
\text { Donohue, K. }\end{array}$ & $\begin{array}{l}\text { Management Science, } \\
2006\end{array}$ & 22 & 130 & 365 \\
\hline $\begin{array}{l}\text { Toward a theory of behavioral } \\
\text { operations }\end{array}$ & Gino, F.; Pisano, G. & $\begin{array}{l}\text { Manufacturing \& } \\
\text { Service Operations } \\
\text { Management, } 2008\end{array}$ & 22 & 72 & 232 \\
\hline $\begin{array}{l}\text { Judgement under uncertainty - } \\
\text { Heuristics and biases }\end{array}$ & $\begin{array}{l}\text { Tversky, A.; } \\
\text { Kahneman, D. }\end{array}$ & Science, 1974 & 21 & 8343 & 34113 \\
\hline $\begin{array}{l}\text { Prospect theory — Analysis of } \\
\text { decision under risk }\end{array}$ & Kahneman D. & Econometrica, 1979 & 19 & 11673 & 37222 \\
\hline $\begin{array}{l}\text { Modeling managerial behavior - } \\
\text { Misperceptions of feedback in a } \\
\text { dynamic decision-making experiment }\end{array}$ & Sterman, J.D. & $\begin{array}{l}\text { Management Science, } \\
1989\end{array}$ & 19 & 879 & 2428 \\
\hline
\end{tabular}

The results of the co-citation analysis yielded six larger clusters and several smaller ones, which were discarded due to their low number of works (less than five) and thus their inability to form their own separate subfields within BOM. The order of the clusters is the same as was identified by Pajek software. However, the names of the clusters are the authors' interpretations based on the content within each cluster. 
The first cluster is the Newsvendor cluster (C1), which mainly deals with the newsvendor/newsboy problem. The second cluster is the Domain base cluster (C2), which includes several papers and editorials that established the core BOM principles. The third cluster is the Bullwhip and inventory optimization cluster (C3), which deals with managerial behavior topics that were widespread even before BOM emerged as a formal field. The fourth cluster is the Social goals cluster (C4), which deals with how social preferences/fairness affect behavior in operations management. The fifth cluster is the Supplier relationship cluster (C5), which deals with questions related to the selection, evaluation, and development of suppliers. The sixth cluster is the Inter-organizational marketing cluster (C6), which connects classic marketing literature with behavioral issues.

Some of the clusters have very clear thought leaders, and some are based on classic works, while some show more diversity. The clusters also include the methodology papers, which gives a valuable insight into the mostprevalent methodologies used within each cluster.

Table 3 shows the number of papers in each cluster by subject area, according to the Academic Journal Guide 2015 (“Academic Journal Guide," 2015). The Academic Journal Guide provides an authoritative and accurate measurement of the quality and appropriate categories of the journals (Bernroider et al., 2013; Wu and Zhang, 2015).

Table 3: Number of papers by subject area, according to the Academic Journal Guide 2015

\begin{tabular}{|l|l|l|l|l|l|l|}
\hline Subject area & C1 & C2 & C3 & C4 & C5 & C6 \\
\hline Operations, Technology and Management & 6 & 27 & 3 & & 17 & 6 \\
\hline Operations Research and Management Science & 12 & 6 & 14 & 2 & 3 & \\
\hline General Management & & 2 & 2 & 2 & 7 & 5 \\
\hline Economics & 8 & 1 & & 7 & 3 & 1 \\
\hline Social Science & & 1 & & & & \\
\hline Psychology & 3 & & 2 & & 5 & \\
\hline Marketing & 2 & & & & 5 & 6 \\
\hline Organization Studies & & & 1 & & & 1 \\
\hline Strategic Management & & & & & & 1 \\
\hline Accountancy & & & 1 & & & \\
\hline Sector Studies & & & & & \\
\hline
\end{tabular}

Table 4 shows the journals with four or more papers in each cluster. The numbers in parentheses are the number of papers in the journal.

Table 4: Journals with more than three papers in each cluster

\begin{tabular}{|l|l|}
\hline Cluster & Journals with the most papers in the cluster \\
\hline C1 & Management Science (9), Manufacturing \& Service Operations Management (5), Econometrica (4) \\
\hline C2 & $\begin{array}{l}\text { Journal of Operations Management (10), Journal of Supply Chain Management (6), Manufacturing } \\
\text { \& Service Operations Management (6), Production and Operations Management (4), Management }\end{array}$ \\
\hline
\end{tabular}




\begin{tabular}{|l|l|}
\hline & Science (4) \\
\hline C3 & Management Science (11) \\
\hline C4 & American Economic Review (4) \\
\hline C5 & Journal of Operations Management (8) \\
\hline C6 & Journal of Marketing (5), Journal of Operations Management (5) \\
\hline
\end{tabular}

Figure 2 shows all six clusters and the connections between them. The graphical distances between clusters indicates the strength of their relations. The thickness of the lines represent how often works from different clusters are cited together. The distance of the Inter-organizational marketing cluster from the other clusters is greater than is depicted in Figure 2; however, it was shortened to improve the visibility.

\section{Figure 2: Connections between communities in behavioral operations management}

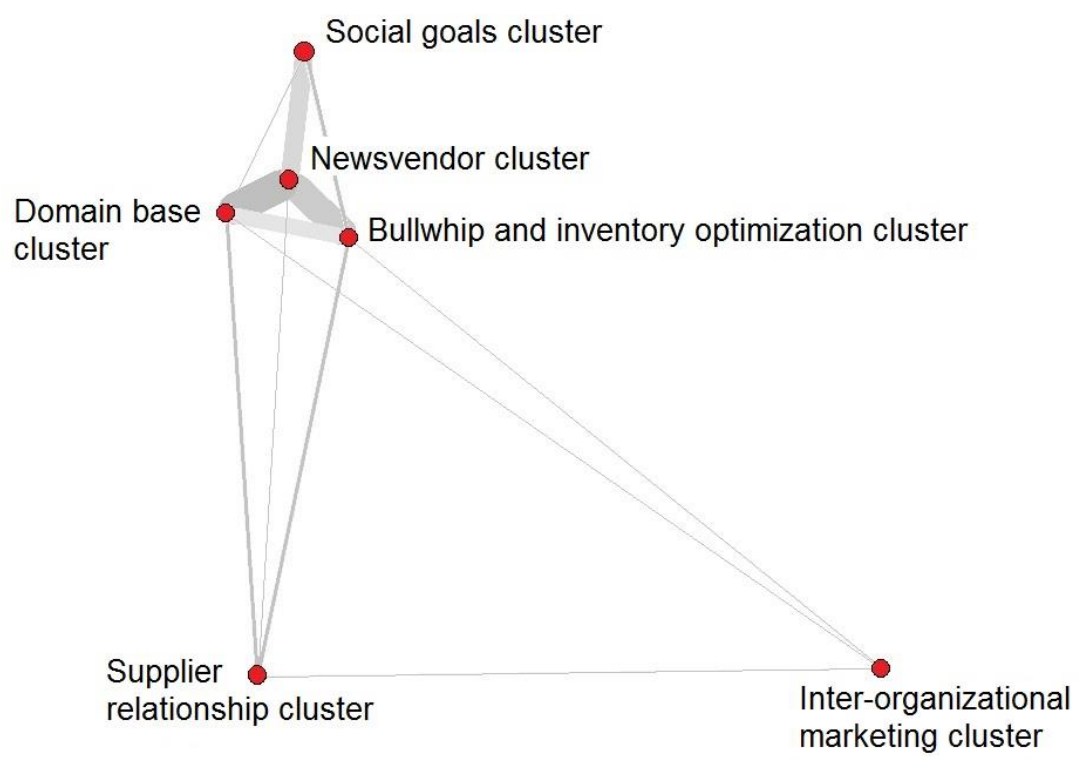

In the following subsections, each cluster is described in detail and is graphically represented.

\subsection{Newsvendor cluster}

The Newsvendor cluster deals almost exclusively with newsvendor/newsboy problems and investigates the irrational but predictable behaviors of newsvendors (Becker-Peth et al., 2013). In the newsvendor problem, an inventory for a single period with stochastic demand has to be ordered. The expected profit-maximizing order quantity is well-known, but the ways in which managers make these decisions in practice is less well-known (Schweitzer and Cachon, 2000). Therefore, the cluster incorporates various additions to the newsvendor problem by, for example, taking the psychological costs of leftovers and stock outs into account (Benzion et al., 2007; Ho et al., 2010). In line with behavioral theory, possible actions to influence the decision maker's experience and feedback are studied (Bolton and Katok, 2008). As such, it is not surprising that the cluster builds on the classic work by Arrow et al. (1951), which deals with uncertainty models in which the optimum stock and the best reordering point are calculated as functions of the demand distribution, the cost of making an order, and the penalty of stock out.

Most models for solving the newsvendor problem adopt a normative approach and assume that decision-makers are perfect optimizers. In contrast, papers in this cluster take a descriptive approach and consider bounded rationality in the sense that decision-makers are prone to errors and biases and fail to adjust sufficiently toward 
the expected profit-maximizing order (Bolton and Katok, 2008; Su, 2008). The papers in this cluster argue that this area has been extensively explored theoretically but has not been tested empirically (Katok and Wu, 2009). Typically, researchers use experiments that investigate newsvendor decision strategies across different profit conditions (Bostian et al., 2008; Katok and Wu, 2009; Kremer et al., 2010; Schweitzer and Cachon, 2000).

Most papers near the center of the cluster therefore investigate a specific aspect of the newsvendor problem, such as the setting of a manufacturer-retailer dyad facing a linear deterministic consumer demand (Lim and Ho, 2007), the differences between experienced procurement managers and students (Bolton et al., 2012), the effect of controlling strategic interactions between a retailer and a supplier (Katok and Wu, 2009), cross-national differences in inventory-ordering patterns between Chinese and American decision-makers (Feng et al., 2011), or actual ordering behavior in multi-location inventory systems (Ho et al., 2010). The popularity of such studies can be attributed to advances in information technology, which has made it possible for decision-makers to track information in real time, obtain frequent feedback on their decisions, react more quickly to changes in the environment, and see the consequences of their actions (Lurie and Swaminathan, 2009).

Near the margin of the cluster, specific studies appear that are not directly connected to the newsvendor problem but investigate similar issues. In one paper, the design of an optimal incentive system that induced task-related effort, cooperation, and knowledge among employees in workgroups was examined (Siemsen et al., 2007).

As such, some would not even consider many papers in this cluster to be typical of the BOM field as defined by a recent wave of research on this topic (Croson et al., 2013) but rather more related to "behavioral game theory" that developed as an extension of "normal" game theory, which began in the 1940s by asking how emotionless geniuses should play games but ignored how average people with emotions and limited foresight actually play a game (Camerer, 2003).

This cluster deals with a relatively well-defined problem from a behavioristic standpoint, because the problem involves one (or two) decision-makers with usually one decision to be made at a certain point in time. As such, it can be modeled relatively easily. Often the optimal decision(s) can be calculated and then compared with the individual's decision in the experiment. Research problems in this cluster are thus suitable for laboratory experiments - ease of replication is a major strength of this approach. Thus, top journals have published a number of research articles, including the ones aimed at replicating previously published results, which focused on testing the laboratory findings, associated behavioral models, and model extensions (Bolton and Katok, 2015).

The Newsvendor cluster can be seen in Figure 3. 


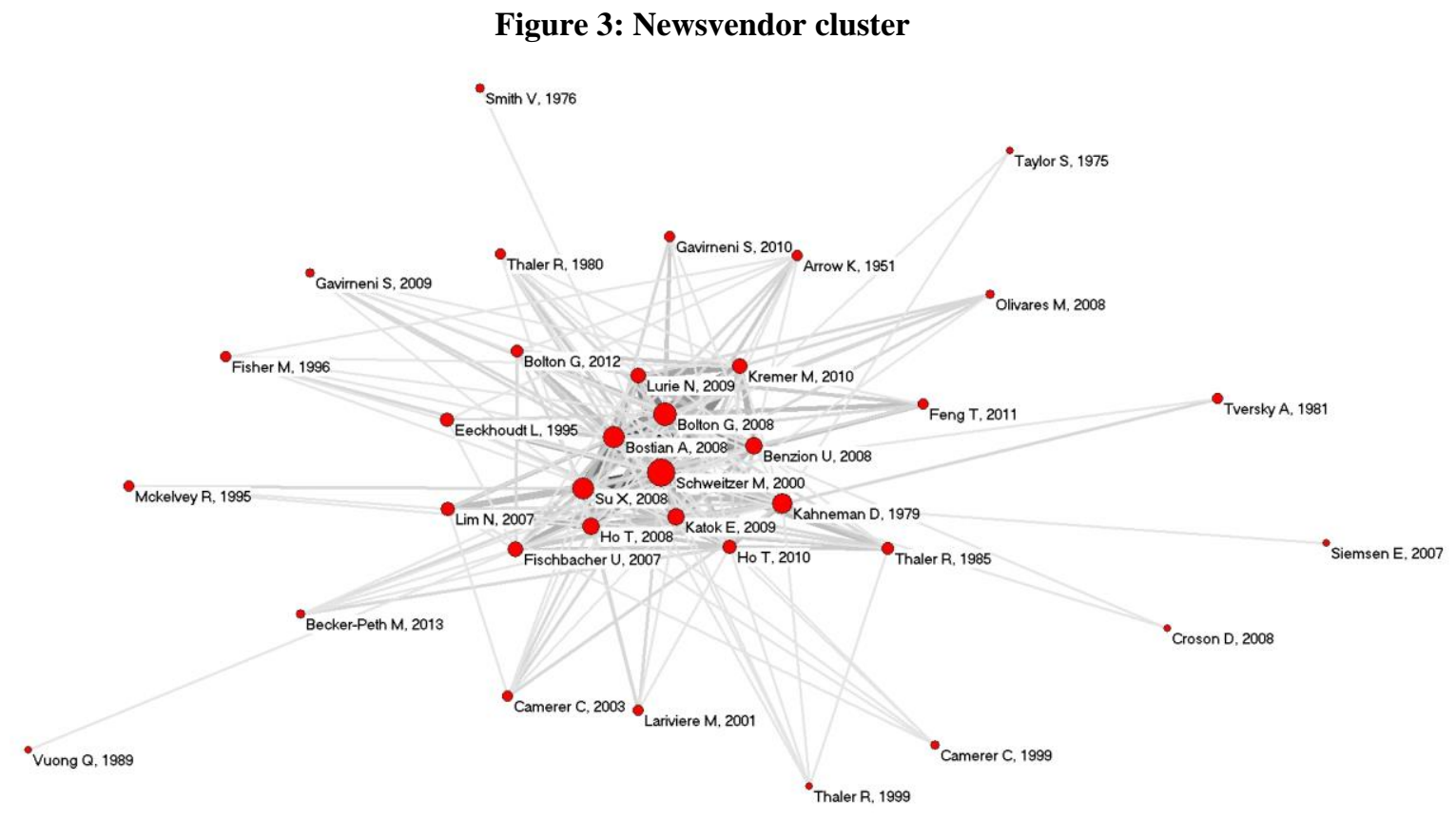

\subsection{Domain base cluster}

The Domain base cluster establishes the domain of BOM and the need for OM scholars to incorporate departures from the rationality assumption in their models and theories. They should explore "the theoretical and practical implications of incorporating behavioral and cognitive factors into models of operations" (Gino and Pisano, 2008). The reasons for non-rational behavior do not lie in poor reasoning but in the fact that the agents often act intuitively (Kahneman, 2003).

The Domain base cluster includes the core domain papers for BOM and the papers, suggesting various methodologies. The cluster is concentrated around the papers of E. Bendoly, who has coauthored $22 \%$ of all papers in the cluster, including two out of the three central papers in the cluster. Those papers analyze the development of the field and propose a framework for BOM (Bendoly et al., 2006), explore the theoretical and practical implications of incorporating behavioral and cognitive factors into models of OM (Gino and Pisano, 2008), and define the major bodies of knowledge that BOM researchers need to tackle (Bendoly et al., 2010).

The editorials for special issues, such as Gans and Croson (2008), and books (Loch and Wu, 2007) also justify identifying this cluster as the core one. Some of the more recent editorials, such as Croson et al. (2013) and Zhao et al. (2013), are missing from this cluster due to the lower number of citations that connect them to the other papers, because editorials often cite only the papers from their issues. Katsikopoulos and Gigerenzer (2013) are also included in other domain specific clusters. Furthermore, the cluster includes the classic papers from the fields that also form the basis for BOM, such as psychology (Edmondson, 1999; Gilovich et al., 2002; Kahneman, 2003) and sociology (Coleman and Coleman, 1990; Granovetter, 1985).

The domain cluster also includes overview papers on subdomains such as revenue management (Bearden et al., 2008; Bitran and Caldentey, 2003) or logistics and supply chain management (Bachrach and Bendoly, 2011; Siemsen, 2011; Tokar, 2010). Most of the papers related to supply chain management are on the margin of this cluster, however (Cantor and Macdonald, 2009; Narasimhan et al., 2009; Oliva and Watson, 2009; Thomas et al., 2011; Wu and Katok, 2006).

From a methodological point of view, most papers promote experimental research (Bachrach and Bendoly, 2011; Flynn et al., 1990; Siemsen, 2011; Stevens, 2011). Methods include laboratory experiments (Eckerd and Bendoly, 2011; Siemsen, 2011), use of simulation games (Amaral and Tsay, 2009; Bearden et al., 2008), and scenario-based role-playing experiments (Rungtusanatham et al., 2011). 
The margin of the cluster also includes some papers that deal with concrete problems, such as Oliva and Watson (2009), who studied managing forecasts in corporate settings, and Thomas, Fugate and Koukova (2011), who deal with knowledge sharing and coordination between supply chain members.

The Domain base cluster can be seen in Figure 4.

Figure 4: Domain base cluster

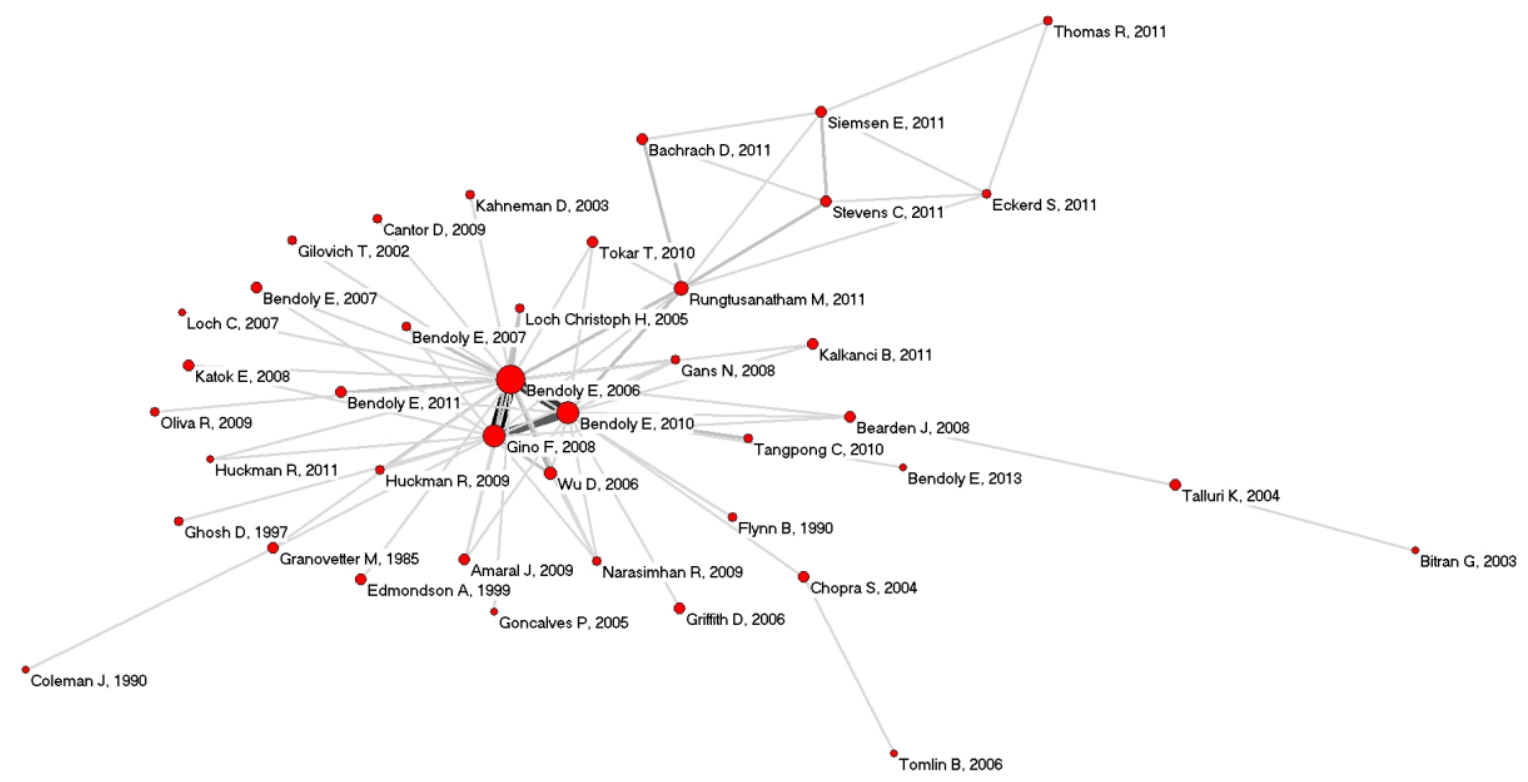

\subsection{Bullwhip and inventory optimization cluster}

In many ways, this cluster could be considered as a BOM before BOM, because the authors attempt to model managerial behavior, mostly in uncertain environments, and it can be seen as an application of experimental economics methods to operations and supply chain management problems (Croson and Donohue, 2002). Papers thus deal with heuristics and biases of judgment under uncertainty and the distinction between intuitive and deliberate thought processes (Kahneman, 2003) in order to better understand the business dynamics (Sterman, 2000; Tversky and Kahneman, 1974). The major topics are heuristics of judgment, risky choice, and framing effects (Kahneman, 2003). The papers try to find various approaches that may alleviate biases in decisionmaking (Croson and Donohue, 2002).

Most of the papers in this cluster deal with various aspects of decision-making when a series of dependent realtime decisions have to be made while the state of the environment changes (Brehmer, 1992). The papers model managerial behavior in decision-making experiments to investigate both the consistency and optimality of decisions (Bowman, 1963; Clark and Scarf, 1960; Sterman, 2000).

In doing so, the cluster understandably builds on extensive research on the bullwhip effect, which is a crucial problem in OM (Forrester, 1958, 1961). Much of BOM research in the past has focused on this effect (Gino and Pisano, 2008), which is the increase in the variation of orders in the upstream supply chain (Croson and Donohue, 2005), and attempts to find the most optimal stock level and purchasing quantities in multi-stage models (Clark and Scarf, 1960). The most-central paper in this cluster studies this phenomenon from a behavioral perspective in a supply chain with information lags and stochastic demand (Croson and Donohue, 2006). Another typical paper analyzes demand forecasting and order lead times in multiple-stage supply chains with and without centralized customer demand information (Chen et al., 2000).

As such, it is not surprising that papers in this cluster often study the potential benefits of information sharing, such as its impact on inventory costs and excess stock (Machuca and Barajas, 2004). Another paper showed that sharing point-of-sale information does help to reduce some components of the bullwhip effect in a stable demand 
setting (Croson and Donohue, 2003). Furthermore, it was shown that access to downstream inventory information reduces the bullwhip effect more than does access to upstream inventory information (Croson and Donohue, 2005).

However, the larger quantity of information can hinder the decision-maker from properly considering even more relevant information (Steckel et al., 2004). Such information can misguide upstream members in their inventory and production decisions (Lee et al., 1997). Even highly trained professionals often cannot comprehend the most basic principles of accumulation, leading to the use of inappropriate heuristics (Cronin et al., 2009). Decision makers have "misperceptions of feedback" and do not take into account control actions and critical feedbacks that have been initiated but have not yet had an effect (Sterman, 1989; Paich and Sterman, 1993). In one such experiment, the effect of time delays and the strength of the feedback loops in inventory management were studied (Diehl and Sterman, 1995).

Given the many human-centered issues, it is not surprising that papers also build on human-related research. Human responses to OM activities can explain anomalies that at first glance seem to be randomness or error variance (Boudreau et al., 2003).

Contrary to most other clusters, some of the papers in this one also deal with the behavioristic aspects of production workers (and not only managers). One paper identified several negative side effects that occur in systems that rely on worker flexibility (Schultz et al., 2003). Another paper used a laboratory experiment to show that workers speed up significantly when they are the cause of idle time on the line (Schultz et al., 1998). Finally, the ability of companies and individuals to recognize, assimilate, and apply new knowledge is also considered, as shown by the appearance of the cornerstone paper on absorptive capacity (Cohen and Levinthal, 1990). Due to this focus on humans, the cluster obviously builds on organizational knowledge creating processes, as is evident by the inclusion of the cornerstone paper on knowledge management (Nonaka, 1994).

The Bullwhip and inventory optimization cluster can be seen in Figure 5.

Figure 5: Bullwhip and inventory optimization cluster

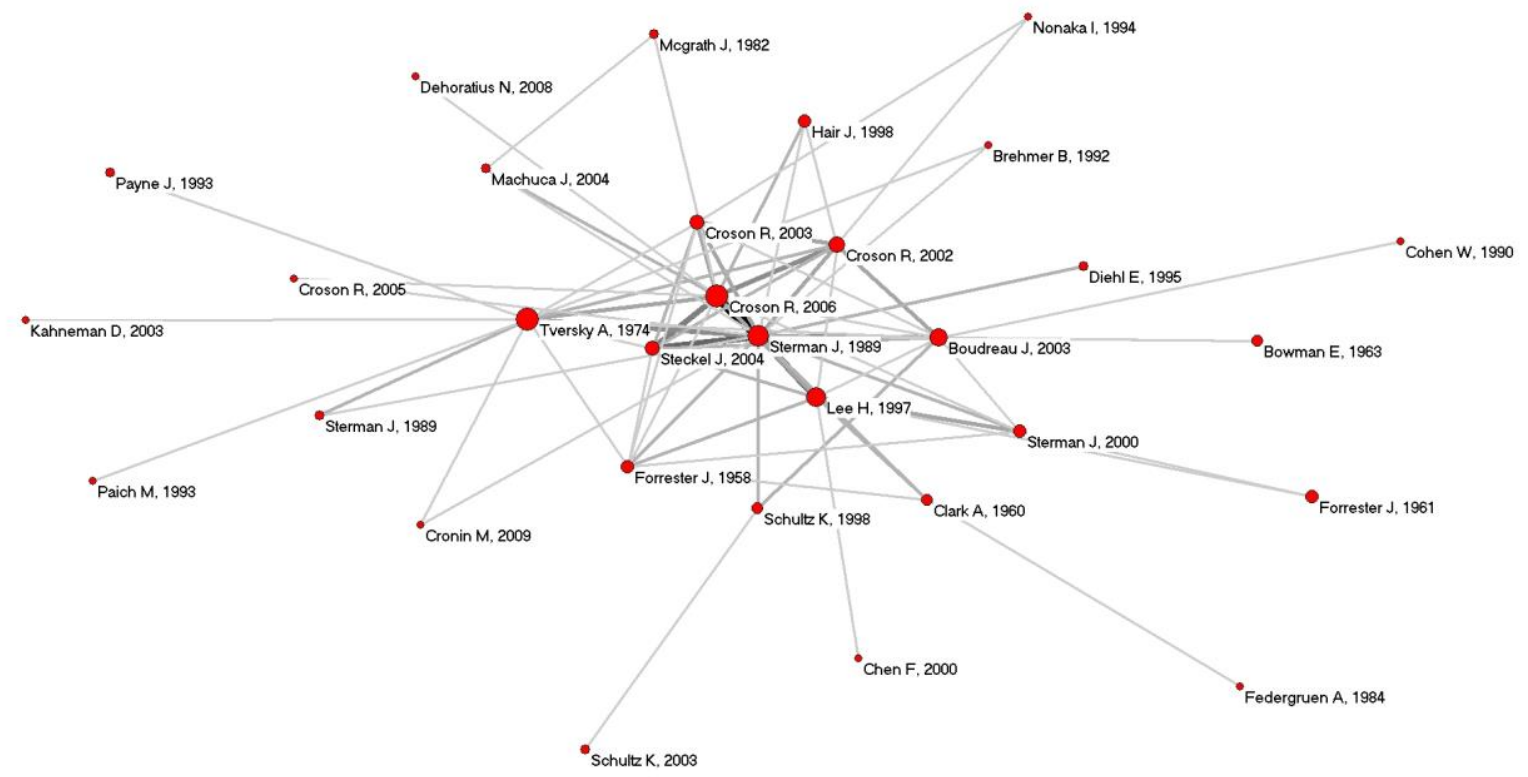

\subsection{Social goals cluster}

This cluster has by far the lowest number of papers, and only two of them were published in the last decade (Haitao Cui et al., 2007; Loch and Wu, 2008). The reason for the small size is that the cluster deals specifically with social goals. The papers in this cluster deal with research on the reasons why people care about social as well as personal goals. 
Central papers in the cluster deal with how an optimal economic equilibrium can be affected by issues caused by social preferences, social exploitation, and fairness. Loch and $\mathrm{Wu}$ (2008) researched how social preferences systematically cause deviations in decision-making in transactions between wholesalers and retailers. Fehr and Schmidt (1999) used the example of bargaining power in competitive markets and bilateral bargaining situations to show that economic environment determines whether the fair or the selfish types of people dominate equilibrium behavior. Cui, Raju, and Zhang (2007) used the concept of fairness in a channel coordination setting.

Most of the other papers in the cluster also deal with general social goals issues applied to different situations within OM; however, some are more general. Bolton and Ockenfels (2000) described a model that denotes three types of behavior, which are equity, reciprocity, and competition. Several papers deal with fairness in different settings, such as the general community standards of fairness (Kahneman et al., 1986), the importance of reciprocity in relation with fairness (Charness and Rabin, 2002), fairness in different economic settings (Rabin, 1993), and fairness and trust in a specific situation such as a manufacturer-retailer relationship (Kumar, 1996). Scheer, Kumar, and Steenkamp (2003) researched the inequality in relationships between organizations and found out that the geographical market affects the reactions to inequity.

The Social goals cluster can be seen in Figure 6.

Figure 6: Social goals cluster

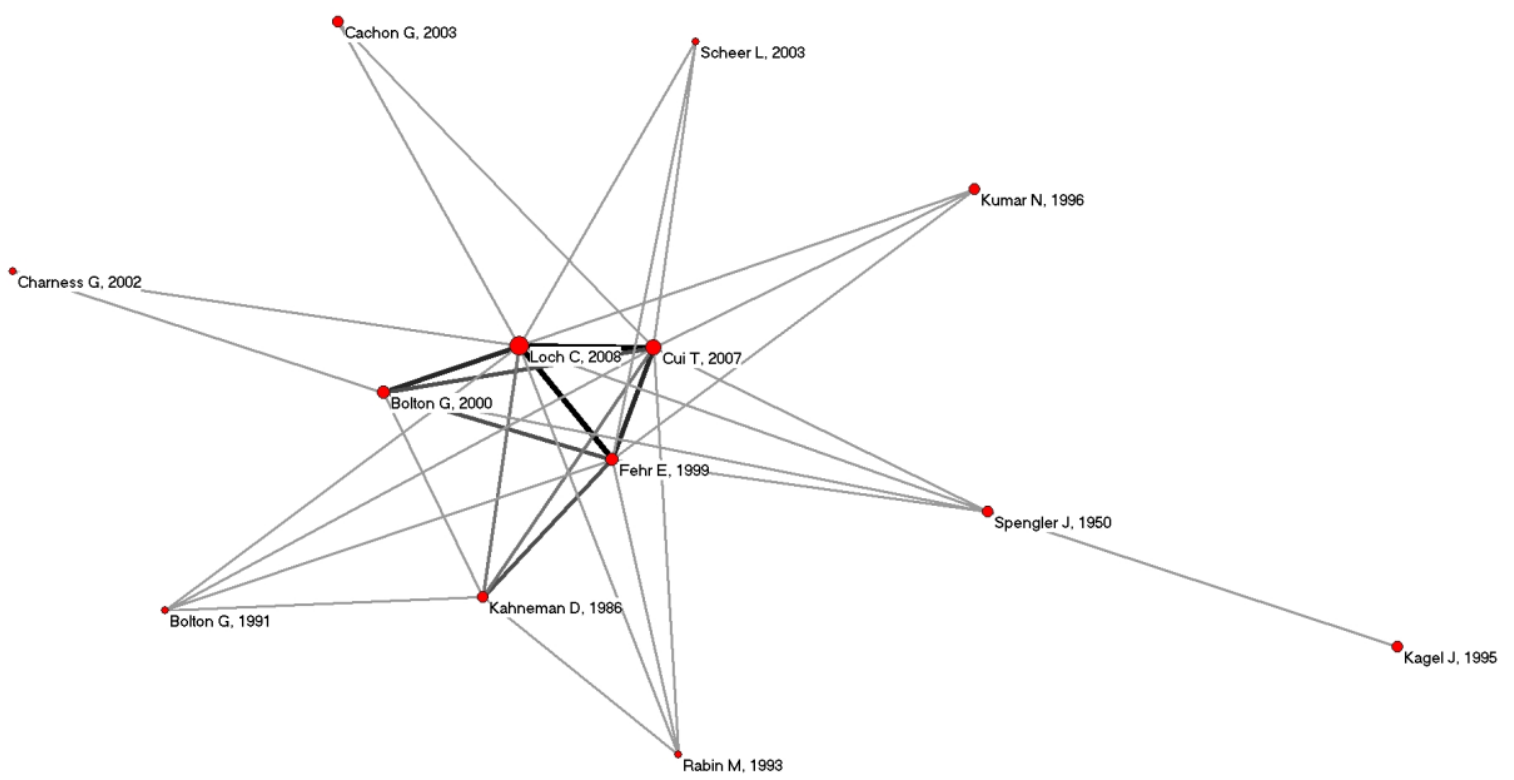

\subsection{Supplier relationship cluster}

The Supplier relationship cluster focuses on behavioral supplier-relationship management. Most papers in the cluster deal with questions related to the selection, evaluation, and development of suppliers. The cluster centers mainly on the works of Carter and Kaufmann, who coauthored five works that appear in the cluster, with three of them being part of the central four works of the cluster.

The central paper in the cluster established a connection between the decision-making bias and supply chain management literature, while also creating a logical taxonomy of biases that can impact supply management decision-making (Carter et al., 2007). The same authors (Kaufmann et al., 2009) also developed a de-biasing framework to help guide future research within the supply chain management context.

The foundations of the cluster come from different domains, such as a review of the criteria and analytical methods used in the vendor selection process (Weber et al., 1991) and a review of decision methods for supporting the supplier selection process (De Boer et al., 2001). Simon (1957) offered a general overview of causation, social processes, motivation, and rationality, and also explained how behaviorism is incorporated into 
the "rational economic man" (Simon, 1955), while Podsakoff et al. (2003) dealt with method biases in behavioral research.

Empirical research is often used in the papers in this cluster. Authors use different data-gathering methods, such as surveys (Kaufmann and Carter, 2006) and structured interviews (Dean and Sharfman, 1993). Structural equation models are often used (Carr and Pearson, 1999; Ellis et al., 2010; Kaufmann and Carter, 2006; Modi and Mabert, 2007; Shin et al., 2000). Therefore, it is of no surprise that two methodological papers on structural equation models (Anderson and Gerbing, 1988; Fornell and Larcker, 1981) are very close to the center of this cluster.

Most other papers address various topics related to supply management. Choi and Hartley (1996) studied supplier selection in the U.S. automotive industry based on whether the position of the supplier in the supply chain was direct or indirect. Kaufmann and Carter (2006) examined the antecedents of the performance of international buyer-supplier relationships. Ellis, Henry, and Shockley (2010) pointed out the importance of behavioral approaches to risk. Mantel, Tatikonda, and Liao (2006) and Dane and Pratt (2007) studied aspects of managerial decision-making; the first paper studied a supply manager's decision to insource or outsource, while the second one explored the role of intuition in managerial decision-making.

The Supplier relationship cluster can be seen in Figure 7.

Figure 7: Supplier relationship cluster

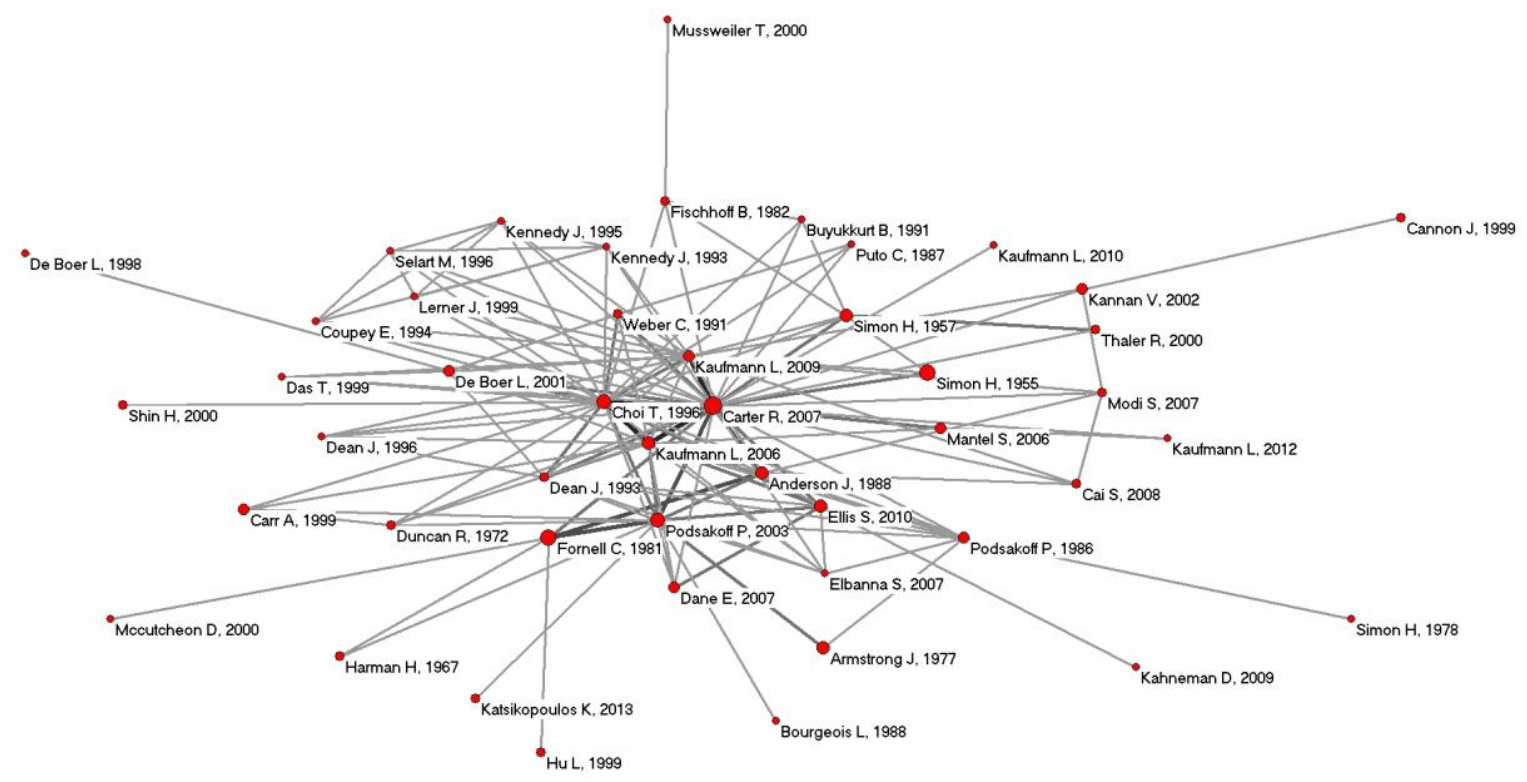

\subsection{Inter-organizational marketing cluster}

The sixth cluster is one of the oldest clusters, as all six of its most-central papers were published before 2000 . The cluster is an interesting connection of the classic marketing literature that dealt with the supplier-buyer relationship on one hand (Dwyer et al., 1987) and the core literature that investigated how/why markets, firms, or even the capitalistic system actually functions on the other (Coase, 1937; Williamson, 1979).

This cluster builds extensively on the claim from Morgan and Hunt (1994) that "relationship marketingestablishing, developing, and maintaining successful relational exchanges" constitutes a major shift. Consequently, the research in this cluster builds on marketing research in an attempt to identify how those relationships develop in supply chains and how to organize the supply chain. The behavioristic aspect of this cluster's research offers deeper insights into either why people make suboptimal decisions or why the choice recommended by the theories is indeed wrong (Katsikopoulos and Gigerenzer, 2013). 
The research in this cluster has increased the attention given to deviations from the standard assumptions of rationality and the focus on the identification and mitigation strategies to de-bias decision-making in operations (Das and Teng, 1998; Kaufmann et al., 2012).

The cluster integrates theories from various fields to analyze the cognitive processes for developing trust in suppliers (Doney and Cannon, 1997) and links the supplier's level of trust to different categories of inter-firm cooperative behaviors (Johnston et al., 2004). The cluster investigates trust and control and their roles in establishing confidence that a partner will not behave opportunistically (Das and Teng, 1998) and improves the understanding of characteristics that influence the success of partnerships (Mohr and Spekman, 1994). Thus, this cluster systematically investigates the antecedents and performance outcomes of inter-organizational communication (Paulraj et al., 2008).

The cluster criticizes a prevailing view: that the main benefit of various inter-organizational arrangements is to reduce the transaction costs due to the self-interested motivations of individuals (Kogut and Zander, 1992). Such a stream of research investigated outsourcing and the efficient governance of contractual relations from the transaction cost economics (TCE) perspective (Williamson, 2008). Previous TCE studies have attracted a growing body of criticism due to its underlying behavioral norm of opportunism (Heide and John, 1992). While one paper surprisingly argued that TCE is an underutilized theoretical lens in the OM discipline (Grover and Malhotra, 2003), most authors agree that it has been used extensively but that guidelines based on TCE logic and assumptions can be both wrong and dangerous for managers (Ghoshal and Moran, 1996).

This diverse base is then used for various concrete problems, such as to investigate the moderating effects of buying context on the relationship between buyers and suppliers (Claycomb and Frankwick, 2004) or for all phases in the supplier selection process (De Boer et al., 2001). Another typical example is a model of buyersupplier relationships which connects a supplier's level of trust to a buyer's perception of a relationship's performance (Johnston et al., 2004), and yet another typical example is an analysis of the U.S. auto industry and its decisions about which suppliers to use (Choi and Hartley, 1996).

Methodologically, papers often use manufacturer-supplier dyads for statistical investigation (Anderson and Barton, 1992; Johnston et al., 2004), such as a study of 57 strategic decisions in 24 companies (Dean and Sharfman, 1993) or a study of 223 purchasing managers and buyers of direct materials (Ellis et al., 2010). In such a way, the research complements the broader-based behavioral decision-making literature, which has often relied upon experimental methodologies that use undergraduate or MBA students (Kaufmann and Carter, 2006; Kaufmann et al., 2012).

While the central papers in this cluster are rather old, this research stream has been partly revitalized with the advent of electronic business, as this significantly decreased transaction costs, and with the nascent BOM research (Kaufmann et al., 2012) from the second cluster. The Internet has decreased transaction costs and increased the use of new tools. For example, one such paper compares e-mail negotiation and Internet reverse auctions with in-person negotiation (Gattiker et al., 2007), while two papers analyze electronic reverse auctions (Beall et al., 2003; Carter and Stevens, 2007).

The Inter-organizational marketing cluster can be seen in Figure 8 . 
Figure 8: Inter-organizational marketing cluster

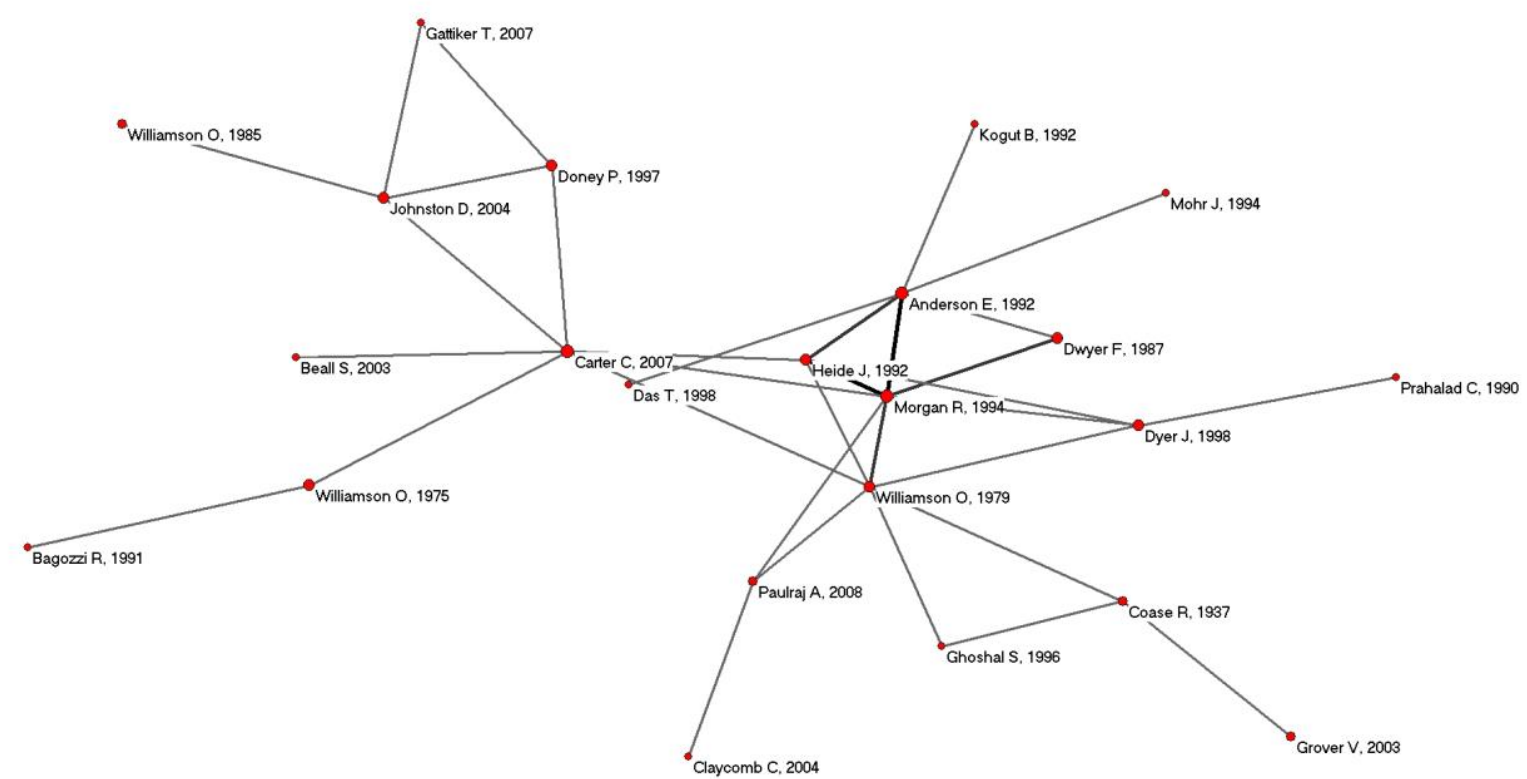

\section{Discussion}

Our paper uses the Lakatosian view to emphasize the need to clearly establish the hard core of the field - the "founding papers" of the field. We use co-citation analysis to stipulate that the Domain base cluster of works represents such a core. We argue that while obviously papers written before the publication of core BOM papers (which mostly appeared after 2005) did not build on this core, any future work should do so in order to be considered part of the BOM literature.

This does not mean that the theoretic core should be fixed and rigid. Only by following the main principles while keeping the field's center plastic will the field increase its legitimacy and practical relevance (adapted from Lyytinen and King, 2004). To paraphrase the research on brain plasticity, BOM should follow the growth factors both within the field and from its environment; it should also increase resistance to over-influence from other fields and improve learning and research performance (Kolb and Whishaw, 1998). Visualization of this plasticity is challenging (Poldrack, 2000). Thus, our proposed use of co-citation analysis for this purpose can improve the visibility of BOM developmental plasticity and consequently enhance the ability to identify and characterize the underlying development of the field.

On the other hand, the protective belt of the field deals with specific problems, some of which can be more clearly identified, such as the research on the bullwhip effect or on the newsvendor problem, while others are more broad and versatile, such as the cluster about social goals. This means that, for example, the research stream on the behavioral aspects of bullwhip effect (Bullwhip and inventory optimization cluster) could decrease without compromising the development of the BOM field in general. In the future, the focus of research on personality traits (Witt et al., 2017) or behavioral aspects of, for example, transport could be more important and would result in a new cluster. Furthermore, there are currently some subfields within the BOM field that are part of the existing clusters in our analysis but that could establish standalone clusters in the future. One such example is BOM in supply chains. While the supplier relation subfield is already a standalone cluster, the other supply chain management topics are currently within the Domain base cluster; they could form their own cluster in the future. On the other hand, we could see a decline in some clusters based on the lack of recent research in their areas, such as in the case of Inter-organizational marketing cluster. Such explorations of the protective belt are crucial for vivid development of the field (in line with Recker, 2014). 
In terms of methodological approach, our paper is the first attempt to use co-citation analysis to analyze and interpret a field in order to define its hard core and protective belt according to Lakatos. A study like this is easily replicable, which is otherwise often a problem in any kind of behavioral/psychological research (Asendorpf et al., 2016), and this enables one to follow the evolution of the field.

Current papers do not contribute much to theory-building in either BOM or OM in general but rather apply theories from other fields (e.g., the theory of absorptive capacity [Cohen and Levinthal, 1990] or transaction costs economics [Ghoshal and Moran, 1996; Grover and Malhotra, 2003]) to BOM problems. Thus, the field suffers from a methodological void - the lack of empirical theory building - similar to the one that OM suffered from decades ago (Swamidass, 1991).

Finally, the managers are becoming more aware of the importance of the BOM field. This paper offers a comprehensive classification of BOM literature, which can help managers to identify the research areas that are relevant for either a general overview of the field or to address their particular problems. Additionally, MBA and $\mathrm{PhD}$ courses can use the findings in this paper as an overview of the field.

\section{Conclusion}

The paper analyzes the intellectual structure of the BOM field, which is quickly developing but is still nascent. Due to its interdisciplinary nature, BOM lacked a consistent classification of existing research efforts that would transform it from a "potentially interesting" and "hyped" research topic into an established and clearly delineated field within OM. Alternatively, BOM could position itself as a subfield within the decision-making or behaviorism fields, which would, however, require its re-framing in order to not just draw from those fields but to contribute to the general work in, for example, behavioral economics (Thaler, 2017).

The paper identifies the major subfields in BOM. In keeping with these findings, BOM researchers should both strengthen the theoretical core and explore the protective belt. Researchers should also look for the use of behavioral theories in conjunction with other subfields of operations management which were not identified as standalone clusters in our research.

Our paper suffers from several limitations. The choice of keywords in the first step of data collection is based on the literature review of the field and as such can suffer from the author's subjective selection. An alternative approach would be to collect and analyze the term occurrences in the papers included in the literature review. When implementing such an analysis, an additional option for visualization of the keywords is a heat map.

The division of clusters into a core and a protective belt and naming them is partly arbitrary and is based on the authors' qualitative assessment of the papers in each cluster; however, the grouping in the clusters and the relations between clusters remain completely unscathed by any researchers' biases. Furthermore, the overreliance on co-citation can lead to overly mechanical classifications of papers, even though we have carefully summarized the contents of the papers.

In addition to the exploration of existing clusters, our analysis offers an excellent starting point to identify and position further research questions. An interesting question arises from the possibility to influence the behavior of employees working in operations (for example, what kinds of trainings for operation managers are most beneficial). It is thus crucial to investigate the effects of interventions (e.g., through human resource management) on the behavior of participants in OM (e.g., how certain interventions change behavior).

Importantly, most BOM protective belt clusters currently deal with well-defined OM problems (such as the bullwhip effect or the newsvendor problem) that are a simplified version of reality. The future research priorities should combine the insights of our analysis with the BOM problems encountered in practice. 
The work outlined in our paper offers an easily replicable methodological approach by which to continue the further development of the core and protective belt of BOM.

\section{Acknowledgements}

The authors acknowledge the project (J5-6816 Business transformation - from business models to innovative processes) was financially supported by the Slovenian Research Agency.

\section{References}

Academic Journal Guide. (2015). Association of Business Schools.

Amaral, J., and Tsay, A. A. (2009). How to win "spend" and influence partners: Lessons in behavioral operations from the outsourcing game. Production and Operations Management, 18(6), 621-634.

Anderson, E., and Barton, W. (1992). The Use of Pledges to Build and Sustain Commitment in Distribution Channels. Journal of Marketing Research, 29(1), 18-34.

Anderson, J. C., and Gerbing, D. W. (1988). Structural equation modeling in practice: A review and recommended two-step approach. Psychological Bulletin, 103(3), 411-423.

Arlbjørn, J. S., and Halldorsson, A. (2002). Logistics knowledge creation: reflections on content, context and processes. International Journal of Physical Distribution \& Logistics Management, 32(1), 22-40.

Arrow, K. J., Harris, T., and Marschak, J. (1951). Optimal Inventory Policy. Econometrica, 19(3), $250-272$.

Asendorpf, J., Conner, M., De Fruyt, F., De Houwer, J., and Denissen, J. (2016). Recommendations for increasing replicability in psychology. Methodological issues and strategies in clinical research, 607-622.

Bachrach, D. G., and Bendoly, E. (2011). Rigor in behavioral experiments: A basic primer for supply chain management researchers. Journal of Supply Chain Management, 47(3), 5-8.

Baker, T., Collier, D., and Jayaraman, V. (2017). Sales force behaviour and best practice pricing drive a product's return on investment. International Journal of Services and Operations Management, 28(3), 335-358.

Beall, S., Carter, C., Carter, P., Germer, T., Hendrick, T., Jap, S., Kaufmann, L., Maciejewski, D., Monczka, R., and Petersen, K. (2003). The Role of Reverse Auctions in Strategic Sourcing. Tempe, AZ, USA: CAPS Research. Bearden, J. N., Murphy, R. O., and Rapoport, A. (2008). Decision biases in revenue management: Some behavioral evidence. Manufacturing \& Service Operations Management, 10(4), 625-636.

Becker-Peth, M., Katok, E., and Thonemann, U. W. (2013). Designing Buyback Contracts for Irrational But Predictable Newsvendors. Management Science, 59(8), 1800-1816.

Becker, K. H. (2016). An outlook on behavioural OR-Three tasks, three pitfalls, one definition. European Journal of Operational Research, 249(3), 806-815.

Bendoly, E., Croson, R., Goncalves, P., and Schultz, K. (2010). Bodies of Knowledge for Research in Behavioral Operations. Production and Operations Management, 19(4), 434-452.

Bendoly, E., Donohue, K., and Schultz, K. L. (2006). Behavior in operations management: Assessing recent findings and revisiting old assumptions. Journal of Operations Management, 24(6), 737-752.

Bendoly, E., van Wezel, W., and Bachrach, D. G. (Eds.). (2015). The handbook of behavioral operations management: Social and psychological dynamics in production and service settings. Oxford University Press.

Benzion, U., Cohen, Y., Peled, R., and Shavit, T. (2007). Decision-making and the newsvendor problem: an experimental study. Journal of the Operational Research Society, 59(9), 1281-1287.

Bernroider, E. W. N., Pilkington, A., and Cordoba, J.-R. (2013). Research in information systems: a study of diversity and inter-disciplinary discourse in the AIS basket journals between 1995 and 2011. Journal of Information Technology, 28(1), 74-89.

Bitran, G., and Caldentey, R. (2003). An overview of pricing models for revenue management. Manufacturing \& Service Operations Management, 5(3), 203-229.

Blondel, V. D., Guillaume, J.-L., Lambiotte, R., and Lefebvre, E. (2008). Fast unfolding of communities in large networks. Journal of statistical mechanics: theory and experiment, $2008(10)$, P10008.

Bolton, G. E., and Katok, E. (2008). Learning by Doing in the Newsvendor Problem: A Laboratory Investigation of the Role of Experience and Feedback. Manufacturing \& Service Operations Management, 10(3), 519-538. 
Bolton, G. E., and Katok, E. (2015). The Importance of Replication in Behavioral Operations Management Retrieved from https:/www.informs.org/Blogs/M-SOM-Blogs/From-M-SOM-Journal-Editor/The-Importanceof-Replication-in-Behavioral-Operations-Management

Bolton, G. E., and Ockenfels, A. (2000). ERC: A theory of equity, reciprocity, and competition. American Economic Review, 90(1), 166-193.

Bolton, G. E., Ockenfels, A., and Thonemann, U. W. (2012). Managers and Students as Newsvendors. Management Science, 58(12), 2225-2233.

Bostian, A. A., Holt, C. A., and Smith, A. M. (2008). Newsvendor "Pull-to-Center" Effect: Adaptive Learning in a Laboratory Experiment. Manufacturing \& Service Operations Management, 10(4), 590-608.

Boudreau, J., Hopp, W., McClain, J. O., and Thomas, L. J. (2003). On the interface between operations and human resources management. Manufacturing \& Service Operations Management, 5(3), 179-202.

Bowman, E. H. (1963). Consistency and Optimality in Managerial Decision Making. Management Science, 9(2), 310-321.

Brehmer, B. (1992). Dynamic decision making: Human control of complex systems. Acta Psychologica, 81(3), 211-241.

Burgess, K., Singh, P., and Koroglu, R. (2006). Supply chain management: a structured literature review and implications for future research. International Journal of Operations \& Production Management, 26(7), 703729.

Camerer, C. (2003). Behavioral game theory: Experiments in strategic interaction: Princeton University Press.

Cantor, D. E., and Macdonald, J. R. (2009). Decision-making in the supply chain: examining problem solving approaches and information availability. Journal of Operations Management, 27(3), 220-232.

Carr, A. S., and Pearson, J. N. (1999). Strategically managed buyer-supplier relationships and performance outcomes. Journal of Operations Management, 17(5), 497-519.

Carter, C. R., Kaufmann, L., and Michel, A. (2007). Behavioral supply management: a taxonomy of judgment and decision-making biases. International Journal of Physical Distribution \& Logistics Management, 37(8), 631-669.

Carter, C. R., and Stevens, C. K. (2007). Electronic reverse auction configuration and its impact on buyer price and supplier perceptions of opportunism: A laboratory experiment. Journal of Operations Management, 25(5), 1035-1054.

Charness, G., and Rabin, M. (2002). Understanding social preferences with simple tests. Quarterly Journal of Economics, 117(3), 817-869.

Chen, F., Drezner, Z., Ryan, J. K., and Simchi-Levi, D. (2000). Quantifying the Bullwhip Effect in a Simple Supply Chain: The Impact of Forecasting, Lead Times, and Information. Management Science, 46(3), 436-443.

Choi, T. Y., and Hartley, J. L. (1996). An exploration of supplier selection practices across the supply chain. Journal of Operations Management, 14(4), 333-343.

Clark, A. J., and Scarf, H. (1960). Optimal Policies for a Multi-Echelon Inventory Problem. Management Science, 6(4), 475-490.

Claycomb, C., and Frankwick, G. L. (2004). A Contingency Perspective of Communication, Conflict Resolution and Buyer Search Effort in Buyer-Supplier Relationships. Journal of Supply Chain Management, 40(4), 18-34.

Coase, R. H. (1937). The Nature of the Firm. Economica, 4(16), 386-405.

Cohen, W., and Levinthal, D. (1990). Absorptive capacity: A new perspective on learning and innovation. Administrative Science Quarterly, 35(1), 128-152.

Coleman, J. S., and Coleman, J. S. (1990). Foundations of social theory: Harvard university press.

Cramér, H. (1945). Mathematical methods of statistics (Vol. 9): Princeton university press.

Cronin, M. A., Gonzalez, C., and Sterman, J. D. (2009). Why don't well-educated adults understand accumulation? A challenge to researchers, educators, and citizens. Organizational Behavior and Human Decision Processes, 108(1), 116-130.

Croson, R., and Donohue, K. (2002). Experimental Economics and Supply-Chain Management. Interfaces, 32(5), 74-82. 
Croson, R., and Donohue, K. (2003). Impact of POS data sharing on supply chain management: An experimental study. Production and Operations Management, 12(1), 1-11.

Croson, R., and Donohue, K. (2005). Upstream versus downstream information and its impact on the bullwhip effect. System Dynamics Review, 21(3), 249-260.

Croson, R., and Donohue, K. (2006). Behavioral Causes of the Bullwhip Effect and the Observed Value of Inventory Information. Management Science, 52(3), 323-336.

Croson, R., Schultz, K., Siemsen, E., and Yeo, M. (2013). Behavioral operations: the state of the field. Journal of Operations Management, 31(1), 1-5.

Dane, E., and Pratt, M. G. (2007). Exploring intuition and its role in managerial decision making. Academy of Management Review, 32(1), 33-54.

Das, T. K., and Teng, B.-S. (1998). Between Trust and Control: Developing Confidence in Partner Cooperation in Alliances. The Academy of Management Review, 23(3), 491-512.

De Boer, L., Labro, E., and Morlacchi, P. (2001). A review of methods supporting supplier selection. European Journal of Purchasing \& Supply Management, 7(2), 75-89.

De Nooy, W., Mrvar, A., and Batagelj, V. (2011). Exploratory social network analysis with Pajek (Vol. 27): Cambridge University Press.

Dean, J. W., and Sharfman, M. P. (1993). Procedural rationality in the strategic decision-making process. Journal of Management Studies, 30(4), 587-610.

Dharamdass, S., and Fernando, Y. (2018). Contact centre service excellence: a proposed conceptual framework. International Journal of Services and Operations Management, 29(1), 18-41.

Diehl, E., and Sterman, J. D. (1995). Effects of Feedback Complexity on Dynamic Decision Making. Organizational Behavior and Human Decision Processes, 62(2), 198-215.

Doney, P. M., and Cannon, J. P. (1997). An Examination of the Nature of Trust in Buyer-Seller Relationships. Journal of Marketing, 61(2), 35-51.

Drejer, A., Blackmon, K., and Voss, C. (2000). Worlds apart? - a look at the operations management area in the US, UK and Scandinavia. Scandinavian Journal of Management, 16(1), 45-66.

Dunn, S. C., Seaker, R. F., and Waller, M. A. (1994). Latent variables in business logistics research: scale development and validation. Journal of Business Logistics, 15(2), 145.

Dwyer, F. R., Schurr, P. H., and Oh, S. (1987). Developing Buyer-Seller Relationships. Journal of Marketing, 51(2), 11-27.

Eckerd, S., and Bendoly, E. (2011). Introduction to the discussion forum on using experiments in supply chain management research. Journal of Supply Chain Management, 47(3), 3-4.

Edmondson, A. (1999). Psychological safety and learning behavior in work teams. Administrative Science Quarterly, 44(2), 350-383.

Ellis, S. C., Henry, R. M., and Shockley, J. (2010). Buyer perceptions of supply disruption risk: A behavioral view and empirical assessment. Journal of Operations Management, 28(1), 34-46.

Fehr, E., and Schmidt, K. M. (1999). A theory of fairness, competition, and cooperation. Quarterly Journal of Economics, 114(3), 817-868.

Feng, T., Keller, L. R., and Zheng, X. (2011). Decision making in the newsvendor problem: A cross-national laboratory study. Omega, 39(1), 41-50.

Flynn, B. B., Sakakibara, S., Schroeder, R. G., Bates, K. A., and Flynn, E. J. (1990). Empirical research methods in operations management. Journal of Operations Management, 9(2), 250-284.

Fornell, C., and Larcker, D. F. (1981). Evaluating structural equation models with unobservable variables and measurement error. Journal of Marketing Research, 18(1), 39-50.

Forrester, J. (1958). Industrial dynamics: a major breakthrough for decision makers. Harvard Business Review, 36(4), 37-66.

Forrester, J. (1961). Industrial Dynamic. Cambridge, MA: MIT Press.

Gammelgaard, B. (2004). Schools in logistics research?: A methodological framework for analysis of the discipline. International Journal of Physical Distribution \& Logistics Management, 34(6), 479-491. 
Gans, N., and Croson, R. (2008). Introduction to the special issue on behavioral operations. Manufacturing \& Service Operations Management, 10(4), 563-565.

Gattiker, T. F., Huang, X., and Schwarz, J. L. (2007). Negotiation, email, and Internet reverse auctions: How sourcing mechanisms deployed by buyers affect suppliers' trust. Journal of Operations Management, 25(1), 184202.

Ghoshal, S., and Moran, P. (1996). Bad for practice: A critique of the transaction cost theory. Academy of Management Review, 21(1), 13-47.

Gilovich, T., Griffin, D., and Kahneman, D. (2002). Heuristics and biases: The psychology of intuitive judgment: Cambridge University Press.

Gino, F., and Pisano, G. (2008). Toward a theory of behavioral operations. Manufacturing \& Service Operations Management, 10(4), 676-691.

Gmür, M. (2003). Co-citation analysis and the search for invisible colleges: A methodological evaluation. Scientometrics, 57(1), 27-57.

Gold, S. (2014). Supply chain management as Lakatosian research program. Supply Chain Management: An International Journal, 19(1), 1-9.

Granovetter, M. (1985). Economic action and social structure: The problem of embeddedness. American journal of sociology, 91(3), 481-510.

Grover, V., and Malhotra, M. K. (2003). Transaction cost framework in operations and supply chain management research: theory and measurement. Journal of Operations Management, 21(4), 457-473.

Haitao Cui, T., Raju, J. S., and Zhang, Z. J. (2007). Fairness and channel coordination. Management Science, 53(8), 1303-1314.

Hämäläinen, R. P., Luoma, J., and Saarinen, E. (2013). On the importance of behavioral operational research: The case of understanding and communicating about dynamic systems. European Journal of Operational Research, 228(3), 623-634.

Hassan, N. R. (2014). Paradigm lost... paradigm gained: a hermeneutical rejoinder to Banville and Landry's 'Can the Field of MIS be Disciplined'. European Journal of Information Systems, 23(6), 600-615.

Heide, J. B., and John, G. (1992). Do Norms Matter in Marketing Relationships? Journal of Marketing, 56(2), $32-44$.

Ho, T.-H., Lim, N., and Cui, T. H. (2010). Reference Dependence in Multilocation Newsvendor Models: A Structural Analysis. Management Science, 56(11), 1891-1910.

Holden, R. J., Scott, A. M. M., Hoonakker, P. L., Hundt, A. S., and Carayon, P. (2015). Data collection challenges in community settings: insights from two field studies of patients with chronic disease. Quality of Life Research, 24(5), 1043-1055.

Johnston, D. A., McCutcheon, D. M., Stuart, F. I., and Kerwood, H. (2004). Effects of supplier trust on performance of cooperative supplier relationships. Journal of Operations Management, 22(1), 23-38.

Kahneman, D. (2003). A perspective on judgment and choice: Mapping bounded rationality. American Psychologist, 58(9), 697-720.

Kahneman, D., Knetsch, J. L., and Thaler, R. (1986). Fairness as a constraint on profit seeking: Entitlements in the market. The American Economic Review, 728-741.

Katok, E., and Wu, D. Y. (2009). Contracting in Supply Chains: A Laboratory Investigation. Management Science, 55(12), 1953-1968.

Katsikopoulos, K. V., and Gigerenzer, G. (2013). Behavioral Operations Management: A Blind Spot and a Research Program. Journal of Supply Chain Management, 49(1), 3-7.

Kaufmann, L., and Carter, C. R. (2006). International supply relationships and non-financial performance-A comparison of U.S. and German practices. Journal of Operations Management, 24(5), 653-675.

Kaufmann, L., Carter, C. R., and Buhrmann, C. (2012). The impact of individual debiasing efforts on financial decision effectiveness in the supplier selection process. International Journal of Physical Distribution \& Logistics Management, 42(5), 411-433.

Kaufmann, L., Michel, A., and Carter, C. R. (2009). Debiasing strategies in supply management decisionmaking. Journal of Business Logistics, 30(1), 85-106. 
Kogut, B., and Zander, U. (1992). Knowledge of the Firm, Combinative Capabilities, and the Replication of Technology. Organization Science, 3(3), 383-397.

Kolb, B., and Whishaw, I. Q. (1998). Brain plasticity and behavior. Annual Review of Psychology, 49(1), 43-64.

Kremer, M., Minner, S., \& Wassenhove, L. N. V. (2010). Do Random Errors Explain Newsvendor Behavior? Manufacturing \& Service Operations Management, 12(4), 673-681.

Kuhn, T. S. (1962). The structure of scientific revolutions: Chicago: University of Chicago Press.

Kumar, N. (1996). The power of trust in manufacturer-retailer relationships. Harvard Business Review, 74(6), 92-106.

Lakatos, I. (1976). Falsification and the methodology of scientific research programmes: Springer.

Larsen, T. J., and Levine, L. (2005). Searching for management information systems: coherence and change in the discipline. Information Systems Journal, 15(4), 357-381.

Le, T. N. (2017). Emotional management and behavioural inhibition system in service failures. International Journal of Services and Operations Management, 27(2), 190-209.

Lee, H. L., Padmanabhan, V., and Whang, S. (1997). Information Distortion in a Supply Chain: The Bullwhip Effect. Management Science, 43(4), 546-558.

Lim, N., and Ho, T.-H. (2007). Designing Price Contracts for Boundedly Rational Customers: Does the Number of Blocks Matter? Marketing Science, 26(3), 312-326.

Loch, C. H., and Wu, Y. (2007). Behavioral operations management: Now Publishers Inc.

Loch, C. H., and Wu, Y. (2008). Social preferences and supply chain performance: An experimental study. Management Science, 54(11), 1835-1849.

Lurie, N. H., and Swaminathan, J. M. (2009). Is timely information always better? The effect of feedback frequency on decision making. Organizational Behavior and Human Decision Processes, 108(2), 315-329.

Lyytinen, K., and King, J. L. (2004). Nothing at the center?: Academic legitimacy in the information systems field. Journal of the Association for Information Systems, 5(6), 8.

Machuca, J. A. D., and Barajas, R. P. (2004). The impact of electronic data interchange on reducing bullwhip effect and supply chain inventory costs. Transportation Research Part E: Logistics and Transportation Review, 40(3), 209-228.

Mantel, S. P., Tatikonda, M. V., and Liao, Y. (2006). A behavioral study of supply manager decision-making: Factors influencing make versus buy evaluation. Journal of Operations Management, 24(6), 822-838.

McCain, K. W. (1990). Mapping authors in intellectual space: A technical overview. Journal of the American Society for Information Science, 41(6), 433.

Melnyk, S. A., Flynn, B. B., and Awaysheh, A. (2017). The best of times and the worst of times: empirical operations and supply chain management research. International Journal of Production Research, 1-28.

Mingers, J. (2000). The contribution of critical realism as an underpinning philosophy for OR/MS and systems. Journal of the Operational Research Society, 51(11), 1256-1270.

Modi, S. B., and Mabert, V. A. (2007). Supplier development: Improving supplier performance through knowledge transfer. Journal of Operations Management, 25(1), 42-64.

Mohr, J., and Spekman, R. (1994). Characteristics of partnership success: Partnership attributes, communication behavior, and conflict resolution techniques. Strategic Management Journal, 15(2), 135-152.

Morgan, R. M., and Shelby, D. H. (1994). The Commitment-Trust Theory of Relationship Marketing. Journal of Marketing, 58(3), 20-38.

Narasimhan, R., Nair, A., Griffith, D. A., Arlbjørn, J. S., and Bendoly, E. (2009). Lock-in situations in supply chains: A social exchange theoretic study of sourcing arrangements in buyer-supplier relationships. Journal of Operations Management, 27(5), 374-389.

Newman, M. E. (2006). Modularity and community structure in networks. Proceedings of the national academy of sciences, 103(23), 8577-8582.

Newman, M. E., and Girvan, M. (2004). Finding and evaluating community structure in networks. Physical review E, 69(2), 026113.

Nikolaidis, Y. (2015). Building a basketball game strategy through statistical analysis of data. Annals of Operations Research, 227(1), 137-159. 
Nonaka, I. (1994). A Dynamic Theory of Organizational Knowledge Creation. Organization Science, 5(1), 1437.

Norris, M., and Oppenheim, C. (2007). Comparing alternatives to the Web of Science for coverage of the social sciences' literature. Journal of Informetrics, 1(2), 161-169.

Oliva, R., and Watson, N. (2009). Managing Functional Biases in Organizational Forecasts: A Case Study of Consensus Forecasting in Supply Chain Planning. Production and Operations Management, 18(2), 138-151.

Paich, M., and Sterman, J. D. (1993). Boom, Bust, and Failures to Learn in Experimental Markets. Management Science, 39(12), 1439-1458.

Pasadeos, Y., Phelps, J., and Kim, B.-H. (1998). Disciplinary impact of advertising scholars: Temporal comparisons of influential authors, works and research networks. Journal of Advertising, 27(4), 53-70.

Paulraj, A., Lado, A. A., and Chen, I. J. (2008). Inter-organizational communication as a relational competency: Antecedents and performance outcomes in collaborative buyer-supplier relationships. Journal of Operations Management, 26(1), 45-64.

Persson, O., Danell, R., and Schneider, J. W. (2009). How to use Bibexcel for various types of bibliometric analysis. Celebrating scholarly communication studies: A Festschrift for Olle Persson at his 60th Birthday, 9-24. Pilkington, A., and Liston-Heyes, C. (1999). Is production and operations management a discipline? A citation/co-citation study. International Journal of Operations \& Production Management, 19(1), 7-20.

Podsakoff, P. M., MacKenzie, S. B., Lee, J.-Y., and Podsakoff, N. P. (2003). Common method biases in behavioral research: a critical review of the literature and recommended remedies. Journal of Applied Psychology, 88(5), 879.

Poldrack, R. A. (2000). Imaging brain plasticity: conceptual and methodological issues — a theoretical review. Neuroimage, 12(1), 1-13.

Popper, K. R. (1972). Objective Knowledge: An Evolutionary Approach. Oxford: Oxford Univ. Press.

Rabin, M. (1993). Incorporating fairness into game theory and economics. The American Economic Review, 83(5), 1281-1302.

Raghuram, S., Tuertscher, P., and Garud, R. (2010). Research note-mapping the field of virtual work: A cocitation analysis. Information Systems Research, 21(4), 983-999.

Recker, J. (2014). Suggestions for the next wave of BPM research: strengthening the theoretical core and exploring the protective belt. JITTA: Journal of Information Technology Theory and Application, 15(2), 5.

Rungtusanatham, M., Wallin, C., and Eckerd, S. (2011). The vignette in a scenario-based role-playing experiment. Journal of Supply Chain Management, 47(3), 9-16.

Sankaranarayanan, K., Castañeda, J. A., and Villa, S. (2018). Future Research in Humanitarian Operations: A Behavioral Operations Perspective. In: The Palgrave Handbook of Humanitarian Logistics and Supply Chain Management, 71-117. Palgrave Macmillan, London.

Scheer, L. K., Kumar, N., and Steenkamp, J.-B. E. (2003). Reactions to perceived inequity in US and Dutch interorganizational relationships. Academy of Management Journal, 46(3), 303-316.

Schildt, H. A., Zahra, S. A., and Sillanpää, A. (2006). Scholarly Communities in Entrepreneurship Research: A Co-Citation Analysis. Entrepreneurship Theory and Practice, 30(3), 399-415.

Schultz, K. L., Juran, D. C., Boudreau, J. W., McClain, J. O., and Thomas, L. J. (1998). Modeling and Worker Motivation in JIT Production Systems. Management Science, 44(12-part-1), 1595-1607.

Schultz, K. L., McClain, J. O., and Thomas, L. J. (2003). Overcoming the dark side of worker flexibility. Journal of Operations Management, 21(1), 81-92.

Schweitzer, M. E., and Cachon, G. P. (2000). Decision bias in the newsvendor problem with a known demand distribution: Experimental evidence. Management Science, 46(3), 404-420.

Shane, S., and Venkataraman, S. (2000). The Promise of Entrepreneurship as a Field of Research. Academy of Management Review, 25(1), 217-226.

Shin, H., Collier, D. A., and Wilson, D. D. (2000). Supply management orientation and supplier/buyer performance. Journal of Operations Management, 18(3), 317-333.

Sidorova, A., Evangelopoulos, N., Valacich, J. S., and Ramakrishnan, T. (2008). Uncovering the intellectual core of the information systems discipline. MIS Quarterly, 32(3), 467-482. 
Siemsen, E. (2011). The usefulness of behavioral laboratory experiments in supply chain management research. Journal of Supply Chain Management, 47(3), 17-18.

Siemsen, E., Balasubramanian, S., and Roth, A. V. (2007). Incentives That Induce Task-Related Effort, Helping, and Knowledge Sharing in Workgroups. Management Science, 53(10), 1533-1550.

Simon, H. A. (1955). A behavioral model of rational choice. The quarterly journal of economics, 69(1), 99-118. Simon, H. A. (1957). Models of man; social and rational. Oxford, England: Wiley.

Singhal, K., and Singhal, J. (2012). Imperatives of the science of operations and supply-chain management. Journal of Operations Management, 30(3), 237-244.

Small, H. (1973). Co-citation in the scientific literature: A new measure of the relationship between two documents. Journal of the American Society for Information Science, 24(4), 265-269.

Sodhi, M. S., and Tang, C. S. (2014). Guiding the next generation of doctoral students in operations management. International Journal of Production Economics, 150, 28-36.

Steckel, J. H., Gupta, S., and Banerji, A. (2004). Supply Chain Decision Making: Will Shorter Cycle Times and Shared Point-of-Sale Information Necessarily Help? Management Science, 50(4), 458-464.

Sterman, J. D. (1989). Modeling Managerial Behavior: Misperceptions of Feedback in a Dynamic Decision Making Experiment. Management Science, 35(3), 321-339.

Sterman, J. D. (2000). Business Dynamics: Systems Thinking and Modeling for a Complex World: McGraw-Hill Education.

Stevens, C. K. (2011). Questions to consider when selecting student samples. Journal of Supply Chain Management, 47(3), 19-21.

Straub, D. (2006). The value of scientometric studies: An introduction to a debate on IS as a reference discipline. Journal of the Association for Information Systems, 7(5), 241-245.

$\mathrm{Su}$, X. (2008). Bounded Rationality in Newsvendor Models. Manufacturing \& Service Operations Management, 10(4), 566-589.

Swamidass, P. M. (1991). Empirical science: new frontier in operations management research. Academy of Management Review, 16(4), 793-814.

Thaler, R. H. (2017). Behavioral Economics. Journal of Political Economy, 125(6), 1799-1805.

Thomas, R. W., Fugate, B. S., and Koukova, N. T. (2011). Coping with time pressure and knowledge sharing in buyer-supplier relationships. Journal of Supply Chain Management, 47(3), 22-42.

Tokar, T. (2010). Behavioural research in logistics and supply chain management. The International Journal of Logistics Management, 21(1), 89-103.

Tversky, A., and Kahneman, D. (1974). Judgment under Uncertainty: Heuristics and Biases. Science, 185(4157), 1124-1131.

Veit, D. R., Lacerda, D. P., Camargo, L. F. R., Kipper, L. M., and Dresch, A. (2017). Towards Mode 2 knowledge production: Analysis and proposal of a framework for research in business processes. Business Process Management Journal, 23(2), 293-328.

Walker, H., Chicksand, D., Radnor, Z., and Watson, G. (2015). Theoretical perspectives in operations management: an analysis of the literature. International Journal of Operations \& Production Management, 35(8), 1182-1206.

Walsham, G. (2012). Are we making a better world with ICTs? Reflections on a future agenda for the IS field. Journal of Information Technology, 27(2), 87-93.

Weber, C. A., Current, J. R., and Benton, W. (1991). Vendor selection criteria and methods. European Journal of Operational Research, 50(1), 2-18.

Weber, R. (2006). Reach and grasp in the debate over the IS core: An empty hand? Journal of the Association for Information Systems, 7(11), 703-713.

White, H. D. (1990). Author co-citation analysis: Overview and defense. Scholarly communication and bibliometrics, 84, 106.

Williamson, O. E. (1979). Transaction-Cost Economics: The Governance of Contractual Relations. Journal of Law and Economics, 22(2), 233-261. 
Williamson, O. E. (2008). Outsourcing: transaction cost economics and supply chain management. Journal of Supply Chain Management, 44(2), 5-16.

Witt, P. W., Baker, T., Ashley, N. W., and Winniford, M. (2017). Is personality a key element of Six Sigma project success?. International Journal of Services and Operations Management, 27(4), 472-523.

Wu, B., and Zhang, C. (2015). Incentive strategy for knowledge transfer in enterprise via e-learning 2.0. International Journal of Innovative Computing, Information and Control, 11(5), 1739-1749.

Wu, D. Y., and Katok, E. (2006). Learning, communication, and the bullwhip effect. Journal of Operations Management, 24(6), 839-850.

Zacharia, Z. G., Sanders, N. R., and Fugate, B. S. (2014). Evolving Functional Perspectives Within Supply Chain Management. Journal of Supply Chain Management, 50(1), 73-88.

Zhao, X., Zhao, X., and Wu, Y. (2013). Opportunities for research in behavioral operations management. International Journal of Production Economics, 142(1), 1-2.

Zupic, I., and Cater, T. (2015). Bibliometric methods in management and organization. Organizational Research Methods, 18(3), 429-472. 